\title{
BMJ Open Death and dying in prehospital care: what are the experiences and issues for prehospital practitioners, families and bystanders? A scoping review
}

\author{
Michelle Myall (D) , ${ }^{1}$ Alison Rowsell, ${ }^{1}$ Susi Lund, ${ }^{1}$ Joanne Turnbull, ${ }^{1}$ Mick Arber, ${ }^{2}$ \\ Robert Crouch, ${ }^{1,3}$ Helen Pocock, ${ }^{4,5}$ Charles Deakin, ${ }^{4,6}$ Alison Richardson ${ }^{1,3}$
}

To cite: Myall M, Rowsell A, Lund $\mathrm{S}$, et al. Death and dying in prehospital care: what are the experiences and issues for prehospital practitioners, families and bystanders? A scoping review. BMJ Open 2020;10:e036925. doi:10.1136/ bmjopen-2020-036925

- Prepublication history for this paper is available online. To view these files, please visit the journal online (http://dx.doi. org/10.1136/bmjopen-2020036925).

Received 10 January 2020 Revised 16 June 2020 Accepted 14 August 2020
Check for updates

(C) Author(s) (or their employer(s)) 2020. Re-use permitted under CC BY. Published by BMJ.

For numbered affiliations see end of article.

Correspondence to Dr Michelle Myall; M.Myall@soton.ac.uk

\section{ABSTRACT}

Objective To identify the factors that shape and characterise experiences of prehospital practitioners (PHPs), families and bystanders in the context of death and dying outside of the hospital environment where PHPs respond.

Design A scoping review using Arksey and 0'Malley's five-stage framework. Papers were analysed using thematic analysis.

Data sources MEDLINE; Embase; CINAHL; Scopus; Social Sciences Citation Index (Web of Science), ProQuest Dissertations \& Theses A\&l (Proquest), Health Technology Assessment database; PsycINFO; Grey Literature Report and PapersFirst were searched from January 2000 to May 2019.

Eligibility criteria for selecting studies Qualitative and mixed methods studies reporting the experiences of PHPs, families and bystanders of death and dying in prehospital settings as a result of natural causes, trauma, suicide and homicide, $>18$ years of age, in Europe, USA, Canada, Australia and New Zealand.

Results Searches identified 15352 papers of which 51 met the inclusion criteria. The review found substantial evidence of PHP experiences, except call handlers, and papers reporting family and bystander experiences were limited. PHP work was varied and complex, while confident in clinical work, they felt less equipped to deal with the emotion work, especially with an increasing role in palliative and end-of-life care. Families and bystanders reported generally positive experiences but their support needs were rarely explored.

Conclusions To the best of our knowledge this is the first review that explores the experiences of PHPs, families and bystanders. An important outcome is identifying current gaps in knowledge where further empirical research is needed. The paucity of evidence suggested by this review on call handlers, families and bystanders presents opportunities to investigate their experiences in greater depth. Further research to address the current knowledge gaps will be important to inform future policy and practice.

\section{INTRODUCTION}

Prehospital care (PHC) is an essential part of the emergency and urgent care continuum in contemporary healthcare systems across
Strengths and limitations of this study

To our knowledge this is the first review to focus on practitioner, family and bystander experience of death and dying in prehospital care.

- The review will help to make better sense of prehospital practitioners, families and bystander experiences and to prioritise, from these perspectives, ways to improve these experiences through support and training that includes ethical issues and challenges faced by the work of death and dying.

- The search strategy aimed to balance sensitivity and precision, and pragmatic decisions helped achieve this balance to target studies most likely to be relevant. However, these decisions may also have increased the risk of missing relevant records.

- A focus on healthcare systems similar to that of the UK was intended to increase transferability of findings. However, differences between these systems, and exclusion of healthcare systems that did not parallel the UK's may limit transferability.

the world ${ }^{12}$ and includes urgent and emergency medical care that patients receive outside of the hospital setting. In the UK, $\mathrm{PHC}$ is provided primarily by regionally based National Health Service (NHS) Ambulance Trusts and comprises other services such as patient transport and NHS 111, a 24-hour online and telephone urgent care service. ${ }^{3}$ In some UK regions services are delivered by other providers, including charities and private companies, but in line with NHS principles remain free at the point of access, with some limited exceptions in England. For example, it is a requirement for some overseas students to pay an NHS surcharge or take out private health cover. However, the system in the UK is not reflected worldwide. In Australia, other than in Queensland and Tasmania, ambulance services are covered either by private health insurance or are out of pocket, unless an individual is eligible for 
a concession such as those over 65 years of age, where cover is free, or in some states offered at a reduced rate. ${ }^{4}$ Ambulance services in the USA are operated by private (for-profit and non-profit) and public entities, and with no free universal healthcare in the USA are typically paid for by private health insurance or federally funded programmes such as Medicare and Medicaid. ${ }^{5}$ Evidence suggests the nature of ambulance provision can influence the service provided. ${ }^{6}$

In the UK there is an increasing demand for PHC services. ${ }^{3}{ }^{4}$ In England for the period 2014-2015 the number of emergency 999 calls to ambulance switchboards totalled 9 million, a rise of over 500000 from the previous year ${ }^{7}$ an increase mirrored in other healthcare systems. ${ }^{89}$ Factors contributing to increasing demand are complex and reflect the extent to which work carried out in PHC has been required to react to changes in other parts of the healthcare system. ${ }^{10}$ For example, ageing populations with complex needs, ${ }^{11}{ }^{12}$ difficulties in accessing general practitioner (also known as primary care physician) services, ${ }^{13}$ and greater patient expectations and how patients seek help ${ }^{14}$ have meant the remit of the service has changed. ${ }^{15}$ As an evolving service prehospital practitioners' (PHP) work has become increasingly varied and complex requiring a clinically trained workforce comprising a variety of staffing combinations, such as medical dispatchers, doctors, paramedics, emergency medical technicians and emergency care practitioners.

The nature of the work of PHPs can range from responding to time-critical emergencies for serious or life-threatening injuries or illnesses, such as cardiac arrests, calls that are less immediately time critical but still serious, to those not considered life threatening. Out-of-hospital cardiac arrest (OHCA) is a lead cause of death in industrialised society, ${ }^{16}{ }^{17}$ and while it represents a small proportion of PHC (approximately $0.5 \%$ of calls to English ambulance services) national response targets place a significant strain on services. In England, during 2014, the ambulance service treated 28729 cases of OHCA alone, ${ }^{18}$ and evidence suggests numbers rising year on year. ${ }^{19}$ It is also important to note that of the 60000 OHCA calls attended by ambulance personnel, where treatment was not appropriate, patient assessment, breaking bad news and supporting family and bystanders were also an essential part of care delivered. Increasingly, the ambulance service also responds to calls for people who have life-limiting conditions and approaching the end of life (EoL). ${ }^{20}$

As first responders to crises that immediately precede death, confronting death and dying is an intrinsic part of the work of PHPs. ${ }^{21}$ When providing care to someone who is dying, or dies, they are often required to make challenging decisions and deal with the clinical and emotional aspects of a situation simultaneously. ${ }^{22}$ This requires management of their own feelings and responses, as well as others present including family and bystanders who may or may not have an established relationship with the person. In some countries PHPs can verify death.
For example, in the UK since 2004, Recognition of Life Extinct guidelines permit qualified PHPs to confirm death and cease resuscitation in the field. ${ }^{23}$ Similarly, in the USA and Canada paramedics can confirm death on scene. ${ }^{2425}$ This aspect of their work has the accompanying responsibility of informing relatives or others present that the patient has died.

The provision of care to someone who is dying, and their relatives, has been identified as one of the most stressful human experiences ${ }^{22}{ }^{26}$ and acknowledged as challenging for healthcare professionals (HCP) generally. ${ }^{27} 28$ For those working in PHC, this may be more complex partly because ambulance crews are immediately required to assess and respond to a situation, ${ }^{26}$ and the transient nature of the job may not present opportunities to establish rapport with a dying patient or their relatives, which may have a lasting impact for survivor families into bereavement. In dealing with death and dying PHPs engage in 'moral work' needed to navigate the difficult ethical challenges they experience in this particular context. These include managing expectations from families and providing patient-centred care that is in the best interests of the patient. The recent global COVID-19 pandemic has posed additional ethical demands on PHPs. ${ }^{29}$ In particular, decision-making may be influenced by the rationing of scarce resources, being unable to provide the level of individual care to patients and families they would under more usual conditions, not being deployed to patients they would have attended previously and leaving patients at home who otherwise would have been transferred ${ }^{30}{ }^{31}$ Such ethical challenges may lead to increasing levels of moral distress ${ }^{32} 33$ for PHPs who are unable to pursue what they consider to be the right course of action due to varying internal and/or external constraints.

To date, little is known about the effects on families and others present, or support mechanisms in place for relatives or bystanders who witness an incident when a patient dies where PHPs attend. Similarly, while we know that PHPs encounter death and dying routinely in the course of their work, we understand less about the nature of this aspect of their job, the impact of dealing with death and dying, how they manage situations where a patient dies especially when they do not always have opportunities to debrief with their colleagues, ${ }^{34}$ or their emotional, psychological, educational and training needs in relation to death and dying.

This review is needed to better inform our understanding about the experiences and needs of PHPs, families and bystanders in the prehospital context of death and dying in order to identify areas for further research.

\section{Aim of the review}

In this paper we present a scoping review that explores evidence guided by the question: What is known about the factors that shape and characterise experiences of PHPs, families and bystanders in the context of death and dying outside of the hospital environment where PHPs respond? 
Table 1 PEO framework

P Population and problems
Family members/bystanders/witnesses/healthcare professionals who have experience of being present when a patient is dying or dies when responded to by prehospital services.

$\begin{array}{lll}\text { E/I } & \text { Exposure/issue } & \text { Death and dying where prehospital services respond. } \\ \mathrm{O} & \text { Outcome/themes } & \begin{array}{l}\text { Experiences and views of death and dying where prehospital services } \\ \text { respond. }\end{array}\end{array}$

Specific objectives were to:

1. Ascertain experiences of PHPs when providing care to patients, and supporting families and bystanders, and their own support and training needs.

2. Understand types of PHPs' behaviours and communication strategies enacted for family members and bystanders.

3. Explore families and bystanders' experiences and needs and identify any existing support mechanisms.

\section{DESIGN AND METHODS}

A scoping review methodology ${ }^{35-37}$ was selected as the most appropriate for systematically mapping the literature and identifying key themes, concepts and gaps in knowledge. We used Arksey and O'Malley's ${ }^{38}$ fivestage framework for scoping reviews which includes identifying the research question, identifying relevant literature, selection, charting the data and collating, summarising and reporting the results. We also used Levac et al's recommendations to strengthen methodological rigour. ${ }^{39}$

\section{Searches and information sources}

Searches were carried out in two stages. Stage 1 comprised an initial search in MEDLINE (OvidSP). The population/problems, exposure/issue, outcome/ themes framework (see table 1) informed search development. Search concepts were captured using subject headings and text-word searches in Title, Abstract and Keyword Heading Word fields. Search results from stage 1 were assessed by the research team. Following analysis of relevant records, additional terms for inclusion in the search strategy were considered. Further strategy development resulted in a final MEDLINE strategy for use in stage 2 (figure 1). This final strategy was run in MEDLINE (OvidSP) then translated appropriately for a range of databases including: Embase (OvidSP), CINAHL Complete (EBSCOhost), Scopus (www.scopus. com), Social Sciences Citation Index (Web of Science), ProQuest Dissertations \& Theses A\&I (Proquest), Health Technology Assessment database (https://www.crd.york. ac.uk/CRDWeb), PsycINFO (OvidSP) and Grey Literature Report (http://www.greylit.org/). In addition, the PapersFirst database was searched. The database searches were supplemented by checking the reference lists of included papers. All searches were completed by May 2019.

\section{Exclusion and inclusion criteria}

Papers were selected using specific eligibility criteria outlined in table 2. Only literature focusing on adult death and dying was included. We excluded papers about children, unless they reported on adult children (those aged $>18$ years) or had a combined focus on adults and children.

\section{Paper selection}

The stage 1 search results were imported into the bibliographical software management package EndNote V.X8.2 and assessed. The stage 2 results were imported into the same EndNote library and results were deduplicated. Stage 2 results remaining after deduplication were assessed. An extensive screening process was undertaken. At the first stage, two independent reviewers (ARo, SL) screened record titles and abstracts for relevance against the screening criteria. Abstracts were double screened (MM) where there were any doubts about eligibility. Full-text papers were screened in pairs (ARo, JT) (MM, SL); both reviewers in each pair independently screened studies for eligibility. A third reviewer resolved eligibility disagreements. Grey literature was reviewed and discussed within the team to agree relevance.

\section{Data extraction}

In line with Arksey and O'Malley's framework data extraction (charting) was multistaged. In stage 1 descriptive characteristics from each included paper were collected. In stage 2 findings and discussion sections of papers were extracted into a data extraction tool. In accordance with Levac et $a l \mathrm{~s}^{39}$ recommendation, two reviewers independently extracted and checked data extraction.

\section{Quality appraisal}

While assessing the quality of literature included is not a requirement of scoping reviews, we undertook quality appraisal of included full-text papers from peer-reviewed journals using the Critical Appraisal Skills Programme (CASP) quality assessment tool-a qualitative checklist ${ }^{40}$ independently conducted by two researchers. CASP identifies 10 core questions but does not define how overall quality scores should be defined. We scored papers out of 10 and expressed a percentage, those scoring $\geq 80 \%$ were rated as high $(\mathrm{H})$, papers between $60 \%$ and $80 \%$ as medium (M) and those rated below $\leq 60 \%$ as low (L) (see table 3). Quality appraisal was primarily conducted to illuminate transparency of design, aims and objectives, and 


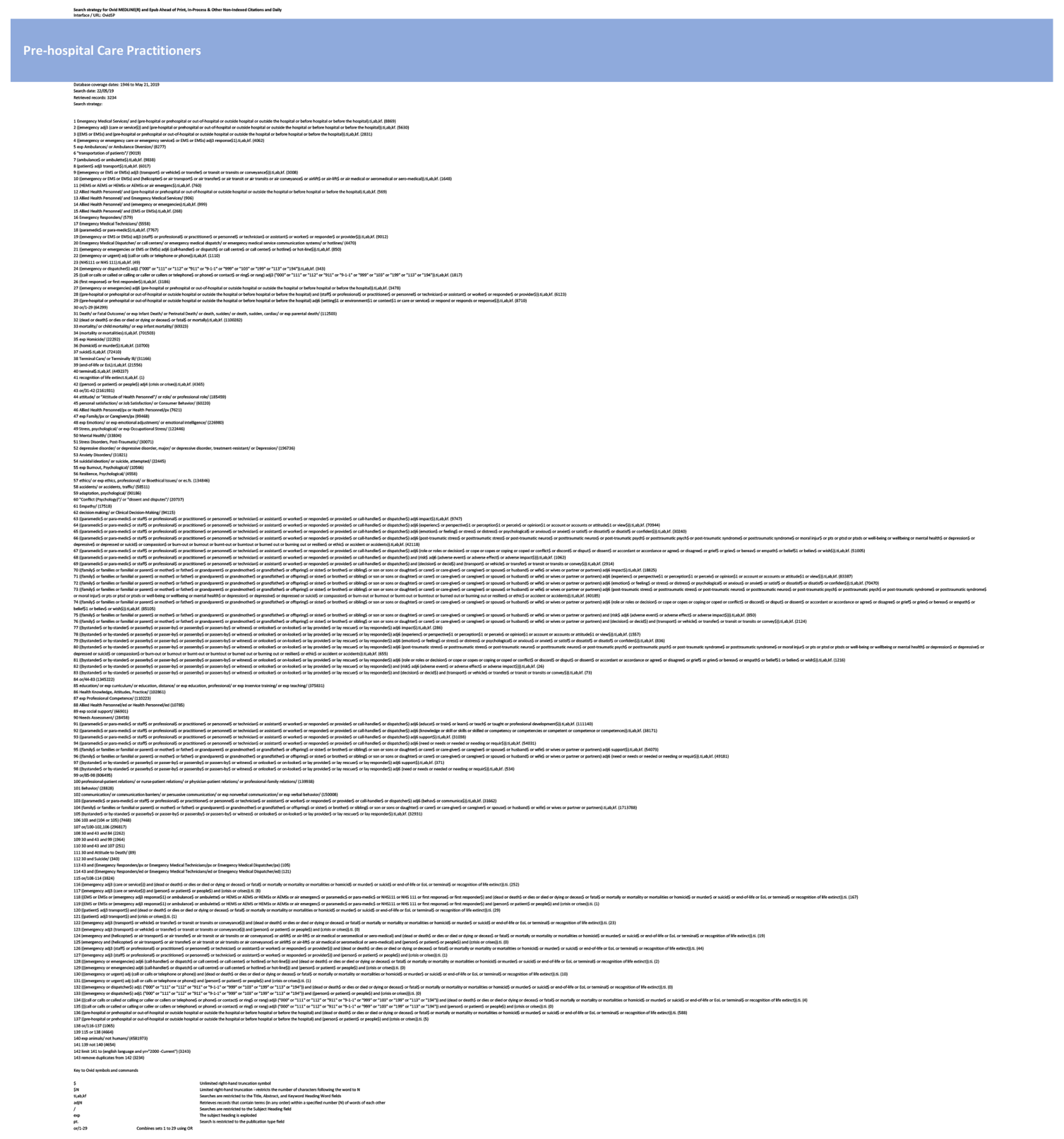

Figure 1 Search strategy.

sample population. However, as is standard to scoping reviews no papers were excluded on grounds of quality. Overall, we scored 29 papers as high quality, 6 medium and 3 low quality. Mixed methods papers with qualitative free-text responses only, conference abstracts, dissertations and book chapters $(n=13)$ were not assessed for quality.

\section{Data analysis}

Data extracted were treated as qualitative data and subject to thematic analysis using Braun and Clarke's approach. ${ }^{41}$ Themes were generated during the full-text review and these were discussed within the review team and grouped together. In line with Arksey and O'Malley's framework for analysis a descriptive overview of findings, rather than a full synthesis of the evidence, is provided. ${ }^{38}$

\section{RESULTS}

Searches identified 15352 records. Following deduplication 8186 records remained for assessment. After assessment, 51 papers were included in the review. Figure 2 shows the review process using the Preferred Reporting Items for Systematic Reviews and Meta-Analyses Extension for Scoping Reviews flow diagram. ${ }^{35} 40$

\section{Characteristics of papers}

Details of included papers are outlined in table 3. Key descriptive information of included papers is as follows: there were 42 journal articles, 5 conference abstracts, 1 book chapter and 3 dissertations. Reported studies were conducted in the UK $(n=16)$, Europe $(n=12)$, USA $(n=9)$, Canada $(n=9)$, Australia $(n=3)$ and New Zealand $(n=2)$. The majority of papers focused on cardiac events $(n=15)$, 
Table 2 Eligibility criteria

Inclusion criteria
Papers reporting studies of adult death and dying in prehospital
settings

Papers reporting studies of death and dying as a result of trauma, suicide and/or homicide

Papers reporting studies of death and dying as a result of
natural causes

Papers reporting studies including families' and/or bystanders' experience of death and dying of a patient where prehospital services respond

\section{Exclusion criteria}

Papers reporting studies of death and dying in healthcare systems outside of Europe, Australia, USA, Canada and New Zealand

Papers reporting studies on response to incidents of death and dying by non-medical emergency services

Papers reporting clinical trials and randomised controlled trials, cohort studies, mixed methods studies without a substantial qualitative element, cost studies

Non-English language papers

Papers published before 1 January 2000 dying or die

Papers published in English language

Papers published between 2000 and 2019

Qualitative and mixed methods studies (with a substantial qualitative element)

\section{Published conference abstracts/papers}

Relevant grey literature from searches (eg, experiences of real clinical practice)

Dissertations and theses

and palliative and end-of-life care (EoLC) experiences in PHC $(n=21)$. Suicide $(n=4)$, critical incidents $(n=3)$ and the impact of this work $(n=8)$ were also a focus. Papers reported on the experiences of PHPs only $(n=39)$, families $(n=2)$, families and PHPs $(n=6)$, bystanders $(n=2)$, bystanders and PHPs $(n=1)$ and bystanders and families $(n=1)$. In terms of methodology 38 papers were qualitative and 13 were mixed methods.

Analysis identified four main themes: experiences of death and dying and its impact; experiences of education and training and unmet needs; support needs and experiences; communication and behaviour. Relevant themes are discussed in relation to the three main stakeholder groups: PHPs, families and bystanders.

\section{PHPs' experiences, education and support needs}

\section{Experience and impact of death and dying}

Experiences of PHPs were characterised by feelings of responsibility towards patients and families and prioritising their needs above their own. There were a number of pressures and stressful tasks identified while attending scenes where dying or death had occurred, including responding alone. ${ }^{42}$ Concerns about legal issues related to resuscitations and ethical dilemmas faced by paramedics were also articulated. ${ }^{43}$ For example, where a do-not-attemptcardiopulmonary-resuscitation (DNACPR) order was in place, but families requested resuscitation efforts. When providing care to patients, and supporting families and bystanders dealing with death and dying, the emotional labour (the process by which workers manage or suppress their feelings to maintain an outward appearance to protect or care for the feelings of others) ${ }^{45}$ was implicit ${ }^{46-48}$ and could result in symptoms of stress and post-traumatic stress disorder. ${ }^{49}$ PHPs also described adverse physiological impacts (eg, on sleep, diet) and an impact on family life. Feelings of failure and guilt and thoughts about what had happened to patients after they reached the hospital emergency department were a concern. Critical incidents, such as premature deaths, ${ }^{50-52}$ suicide, ${ }^{46} 52-54$ OHCA and failed resuscitations, ${ }^{55}$ were especially characterised by intense emotional labour and feelings of inadequacy.

In the UK, USA and Canada an increasing demand for PHPs to support patients at EoL was reported. Papers focused on PHPs' perceptions of providing EoLC, ${ }^{43} 56-58$ EoL calls, ${ }^{215960}$ hospital transfer/transport ${ }^{566162}$ and EoLC setting transitions. ${ }^{62} 63$ Decision-making about keeping patients close to the EoL at home was complex and experiences of EoLC provision were characterised by emotional labour, ${ }^{64}$ care crises, lack of coordination, a need for mediation between services ${ }^{59}$ and gaps in communication. ${ }^{57596065}$ PHPs often found it difficult to ascertain patients' EoL wishes. This was compounded by uncertainty and lack of availability of EoL advance directives and care planning, which hindered their ability to keep patients at home. ${ }^{4456} 65$ PHPs faced a range of system-level barriers and poor EoLC coordination between services. ${ }^{62}{ }^{66}$ Informing families of death was also noted as an especially stressful, time-consuming and challenging task. ${ }^{24}$ 


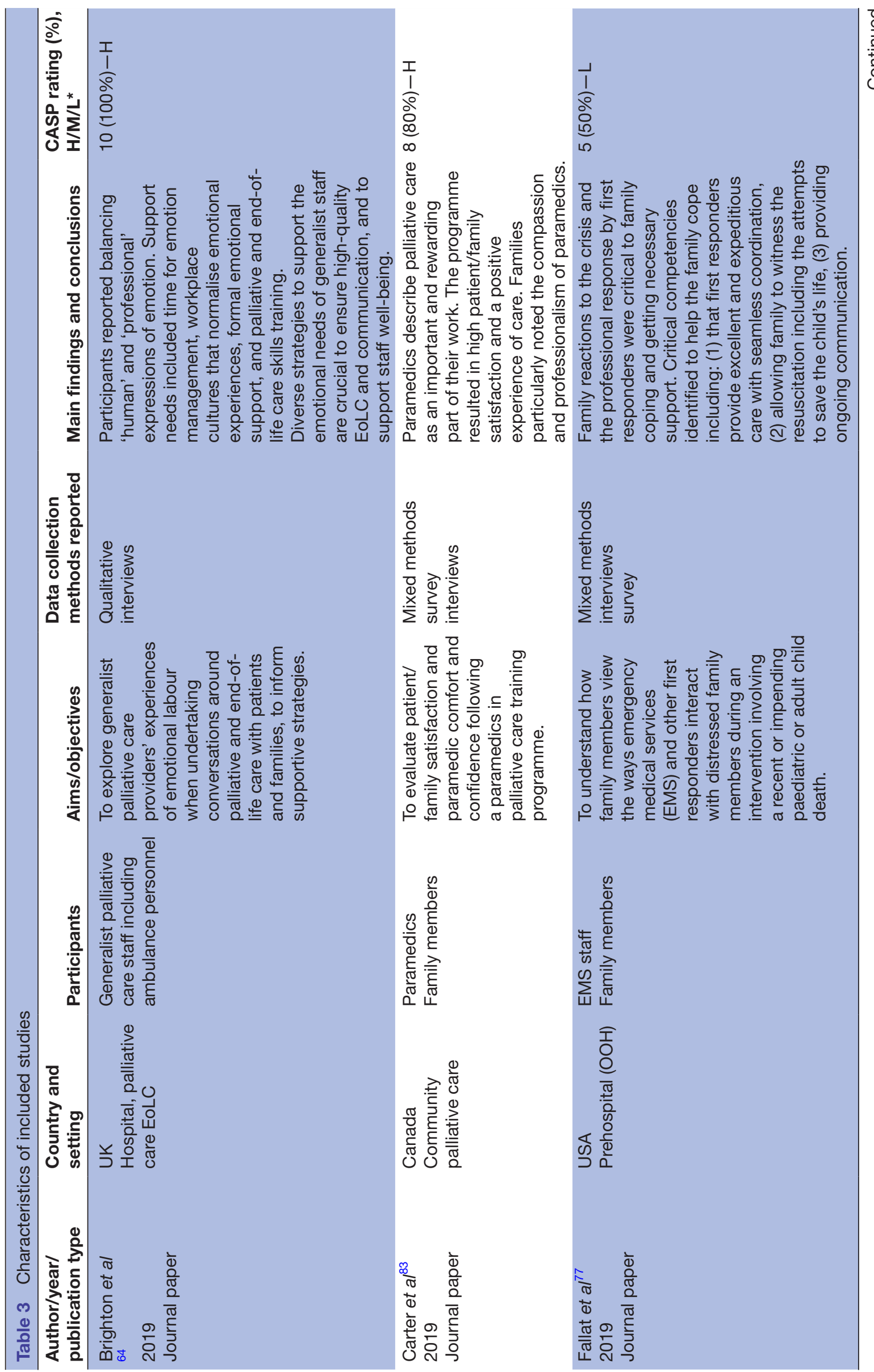




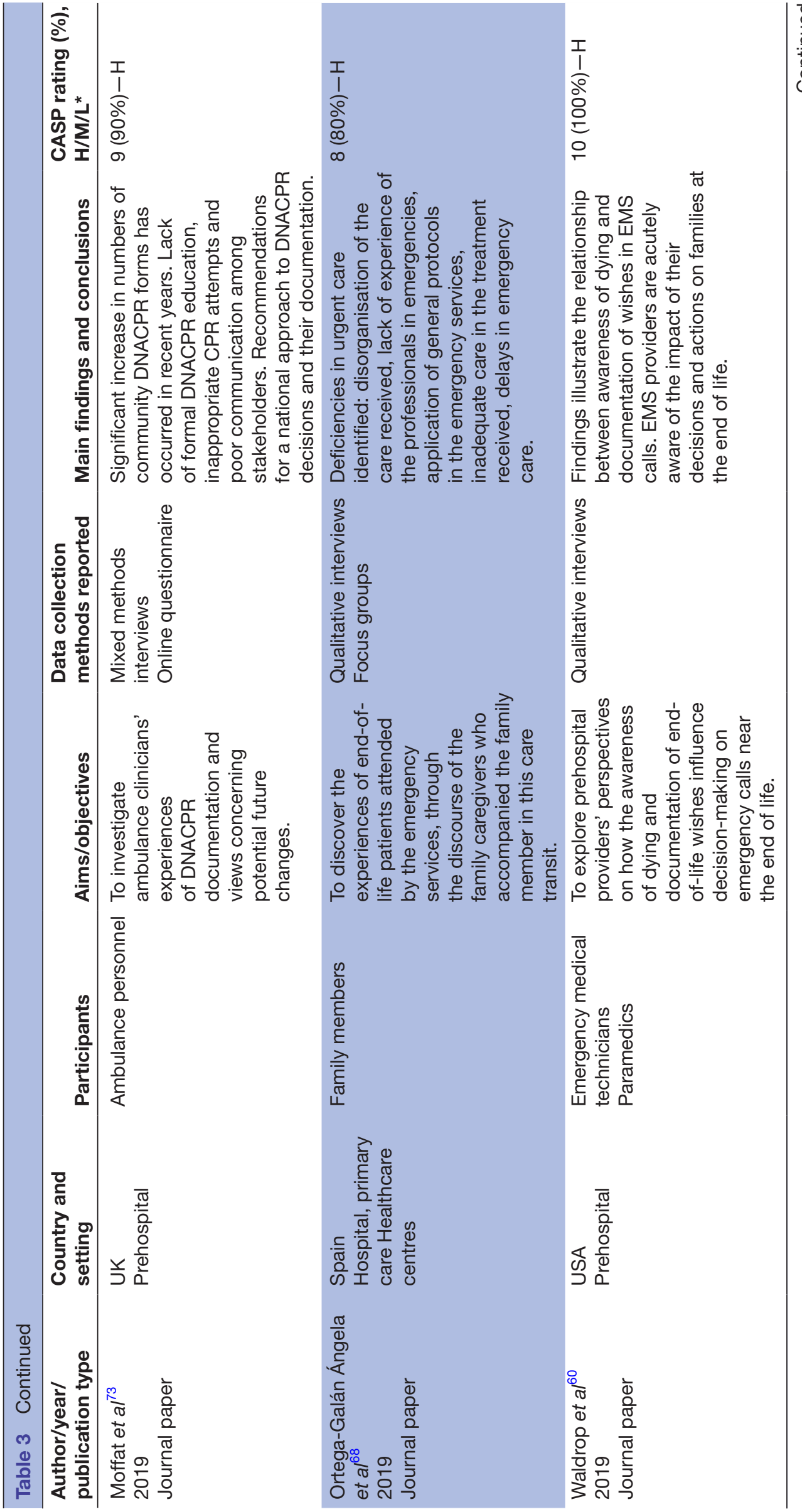




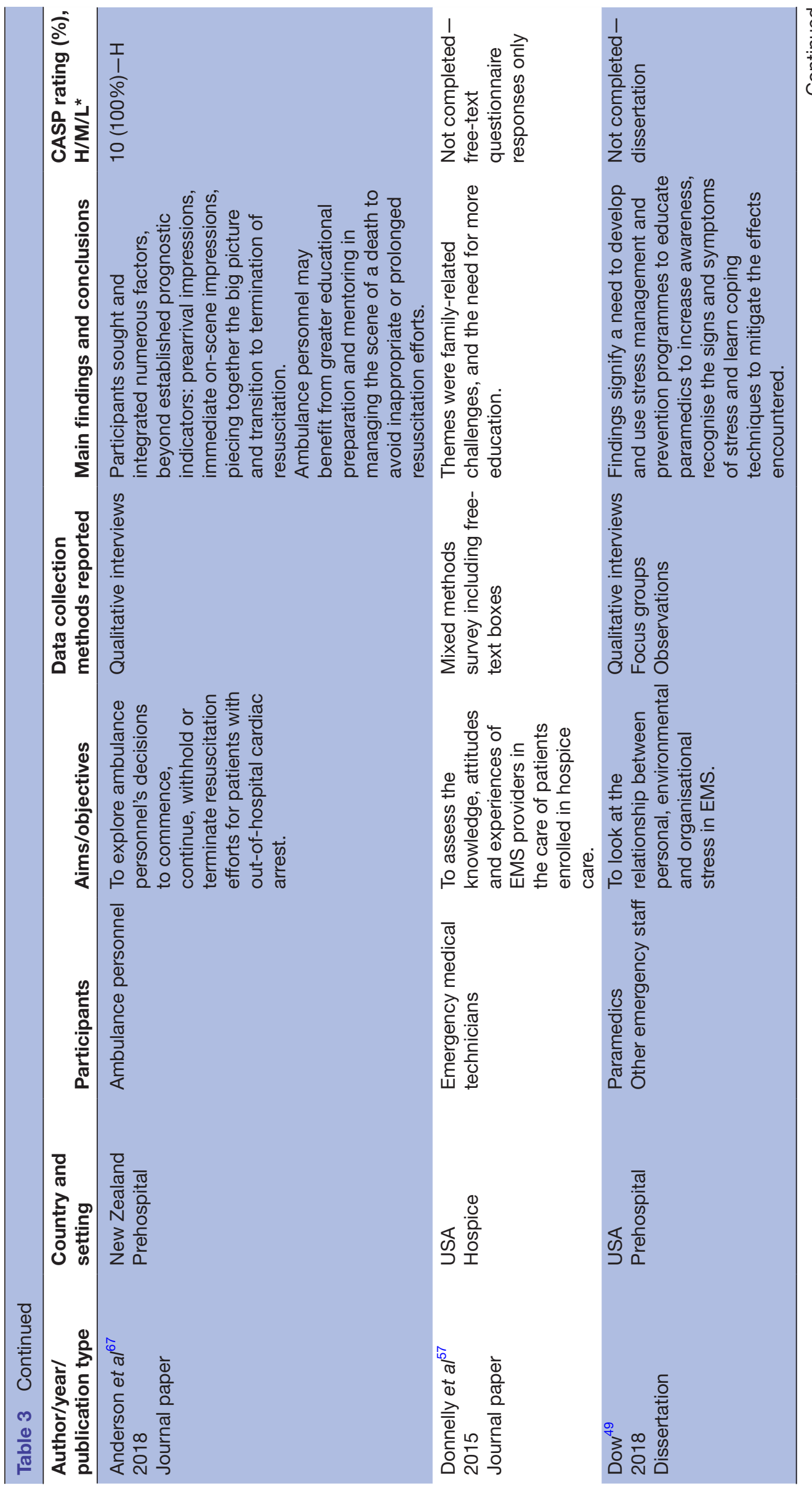




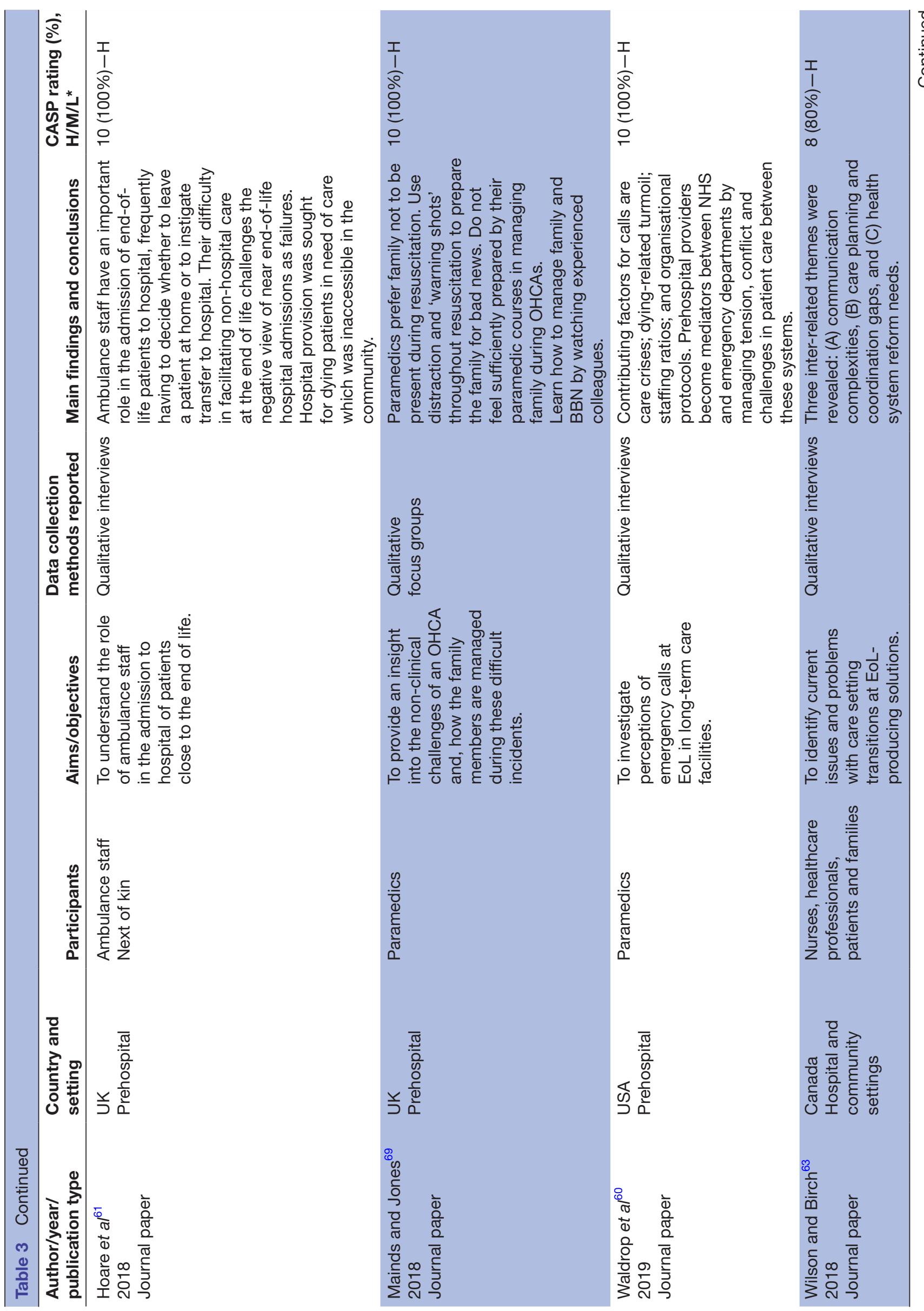




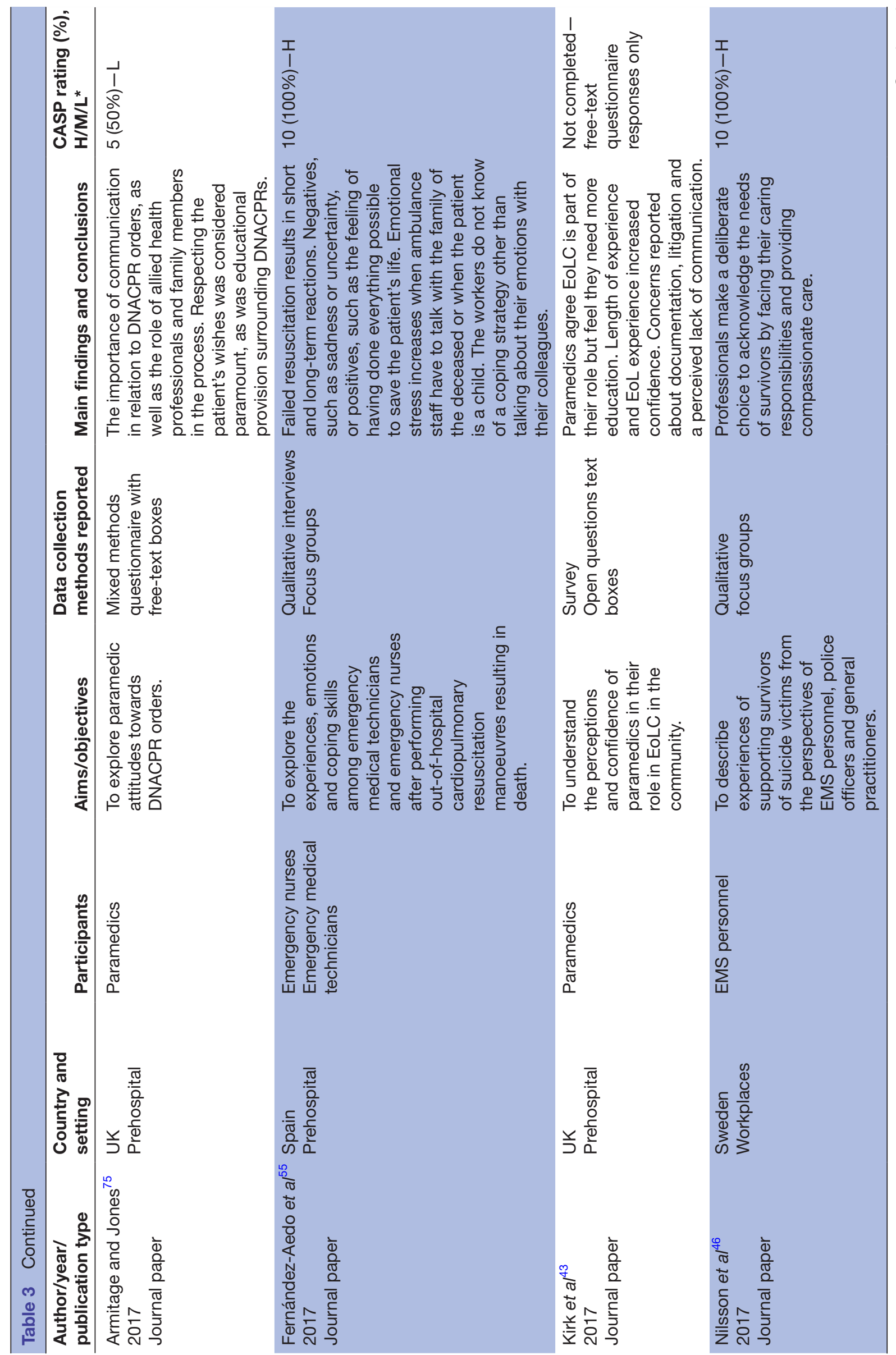




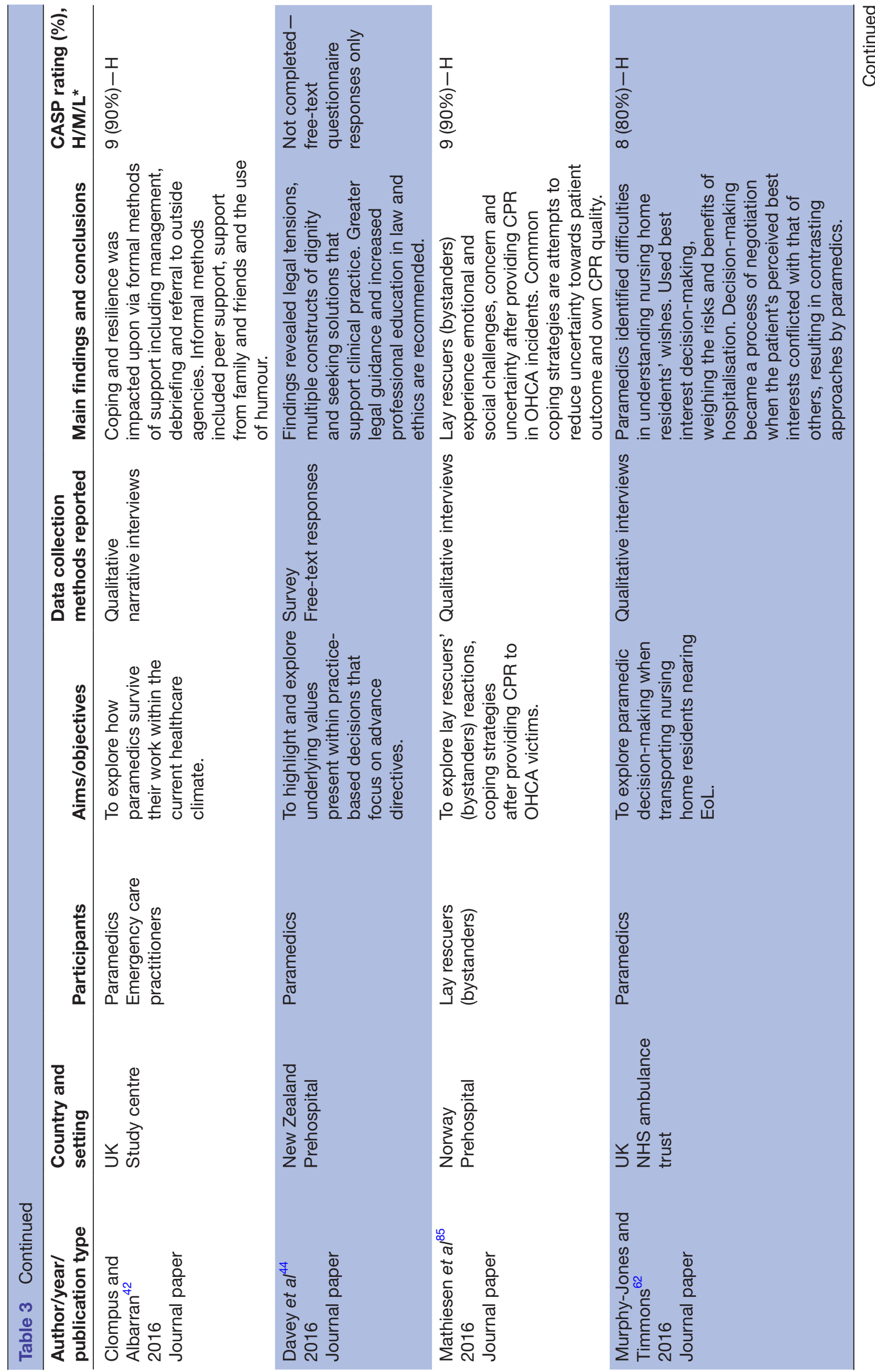




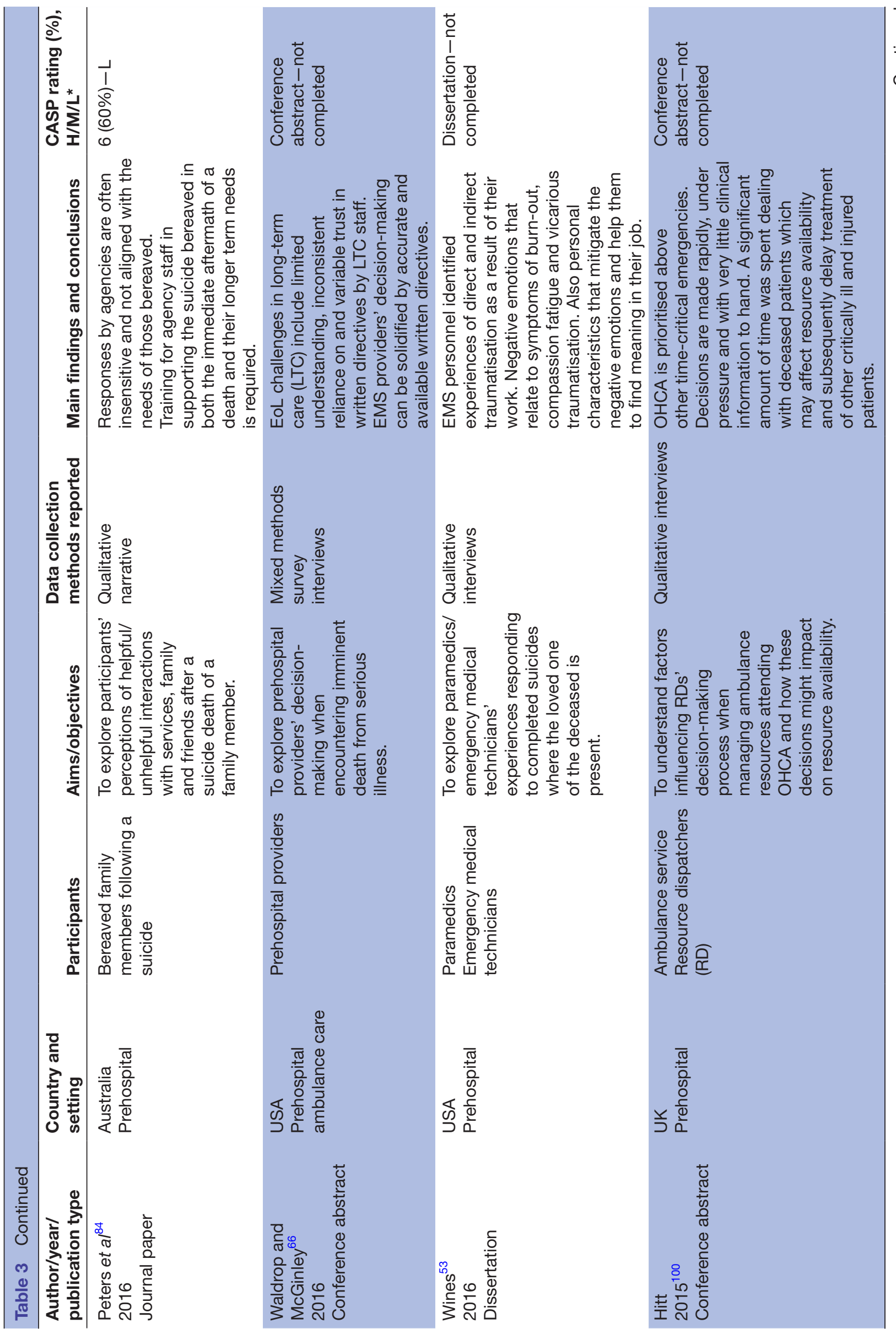

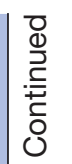

एٕ 


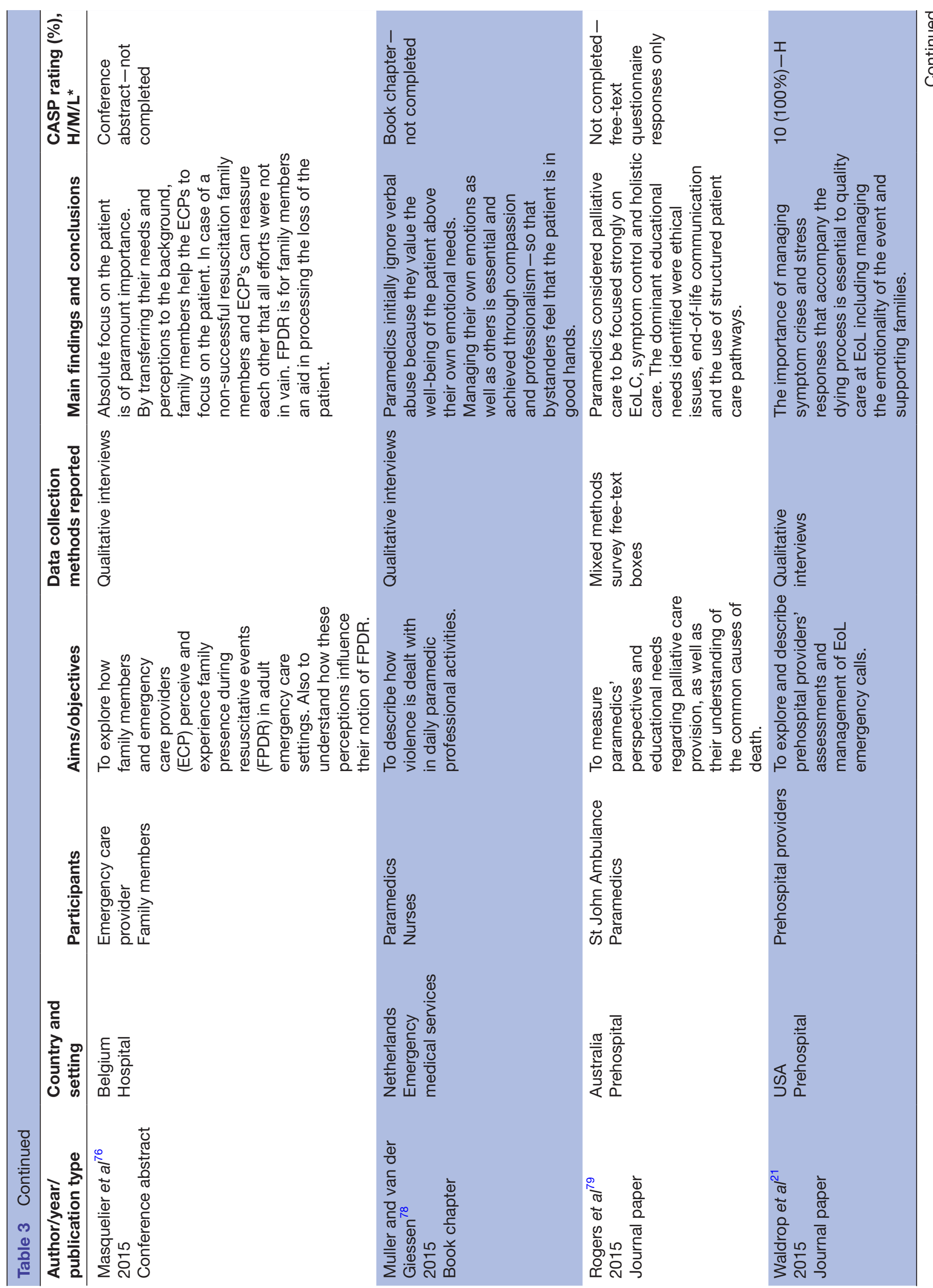




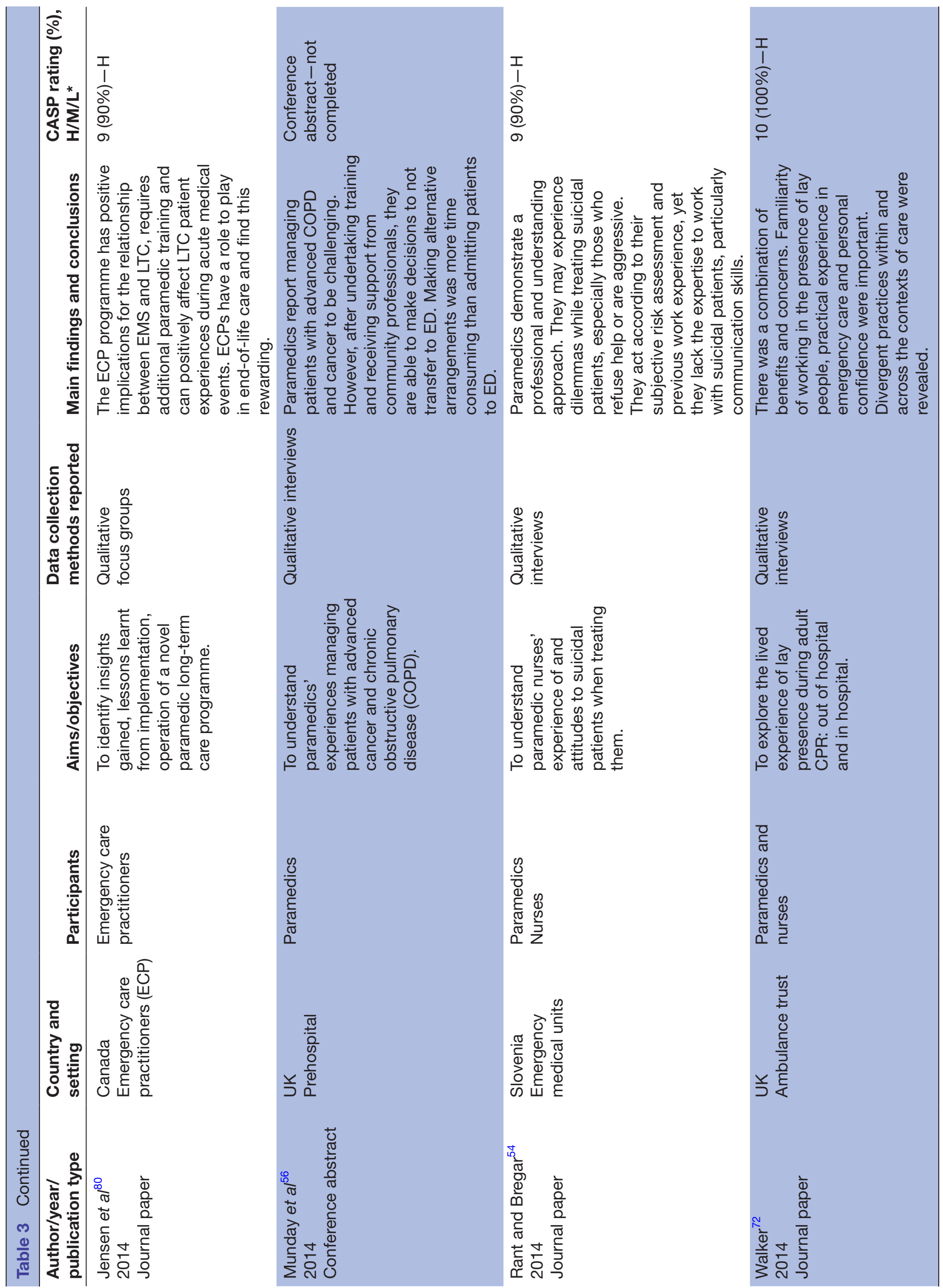




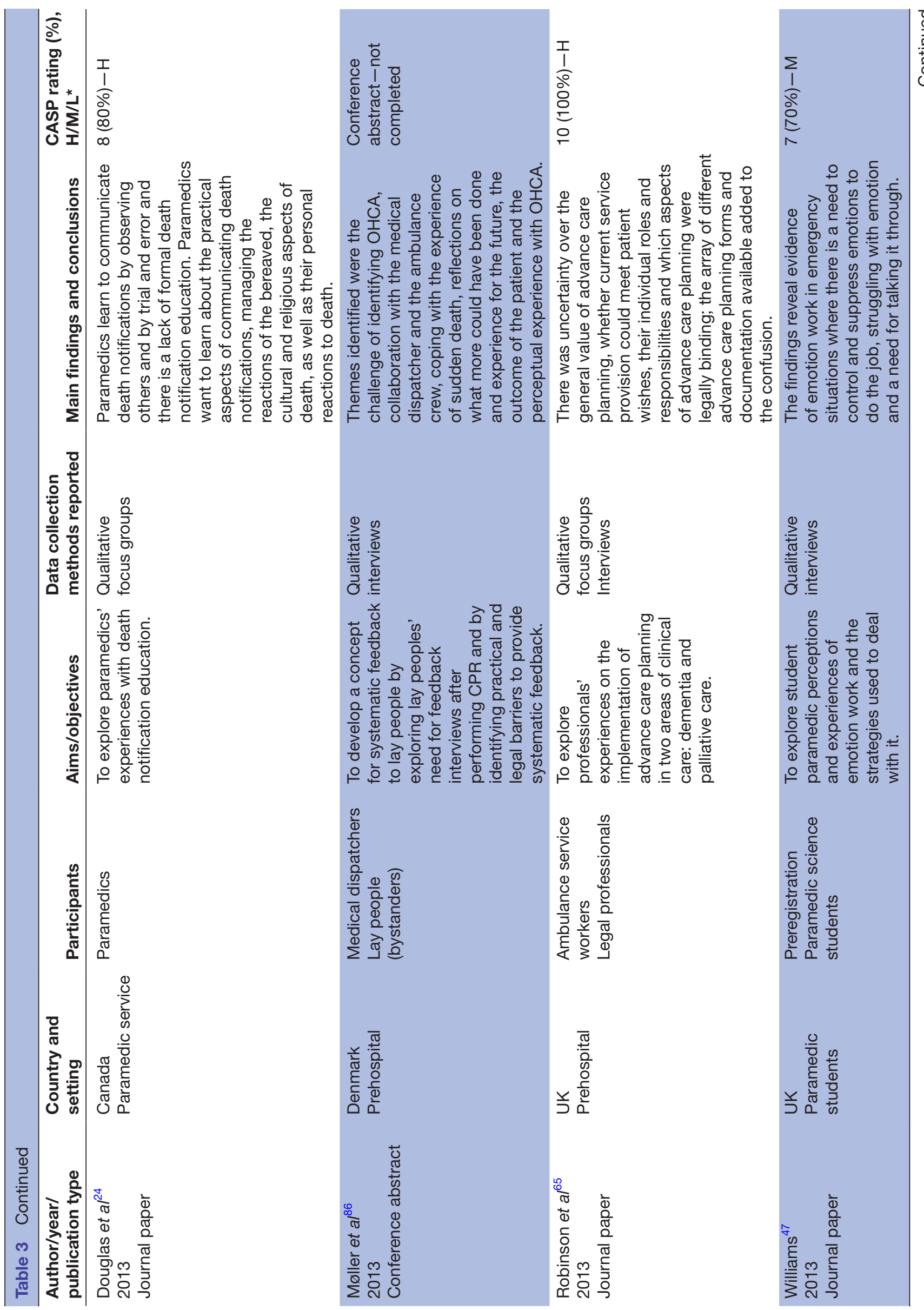




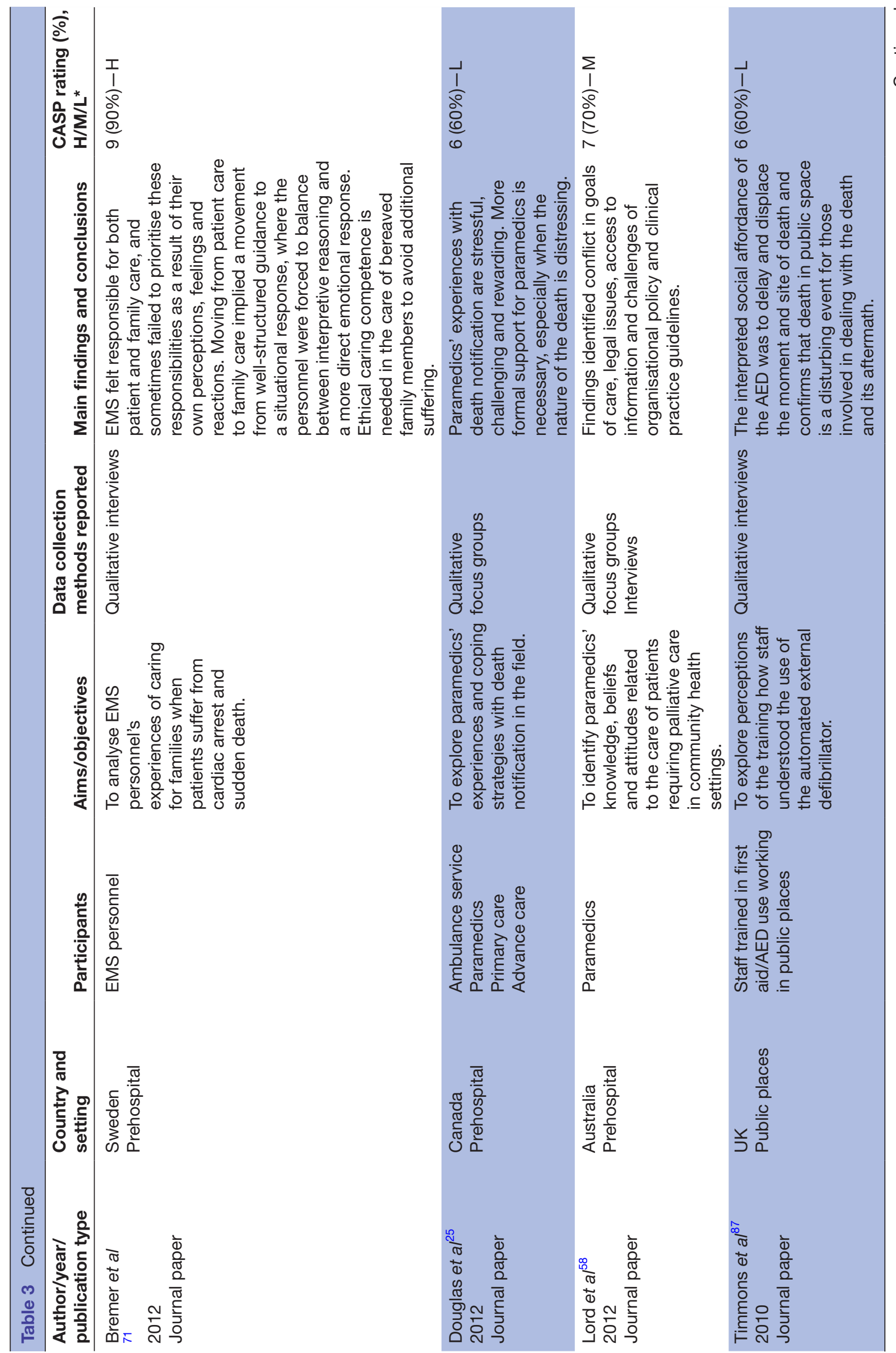




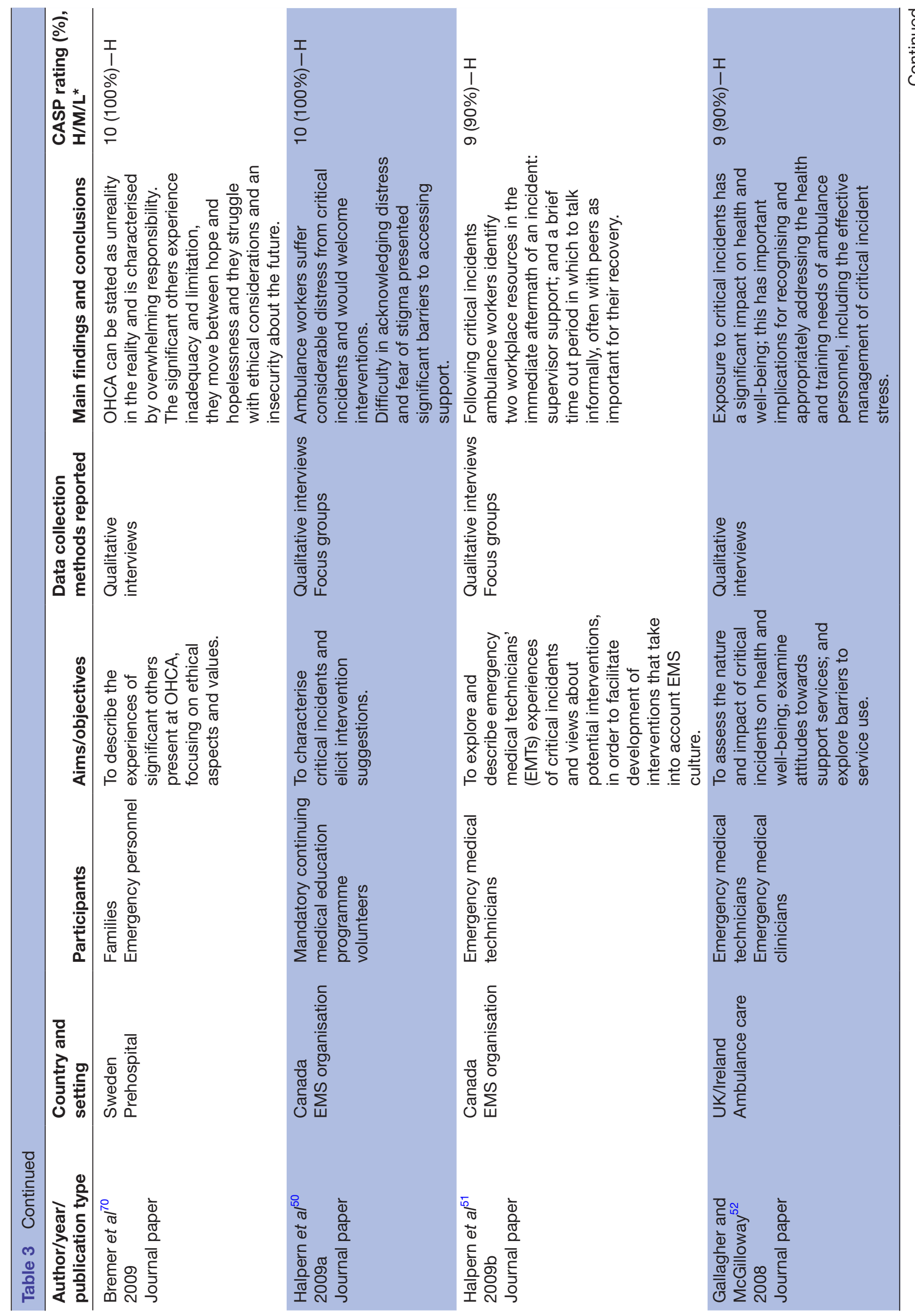

एᄆ

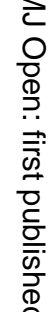

क

。

$\overrightarrow{\vec{\omega}}$

응.

通

N

这

ज

을

$\vec{\infty}$

D

융

N

뭉

ฏ

ฉั

윽

륭

혹

긍.

음. 


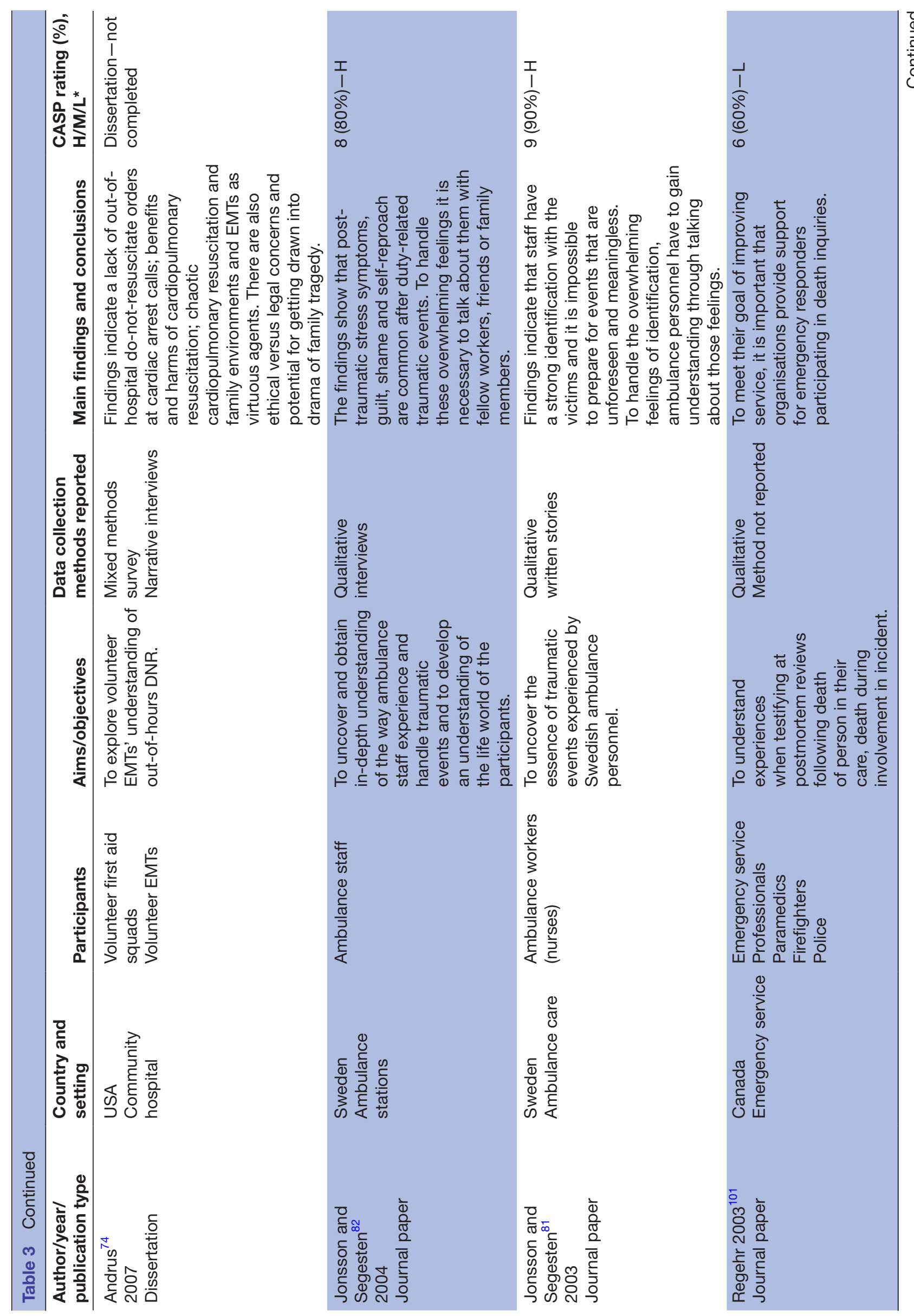



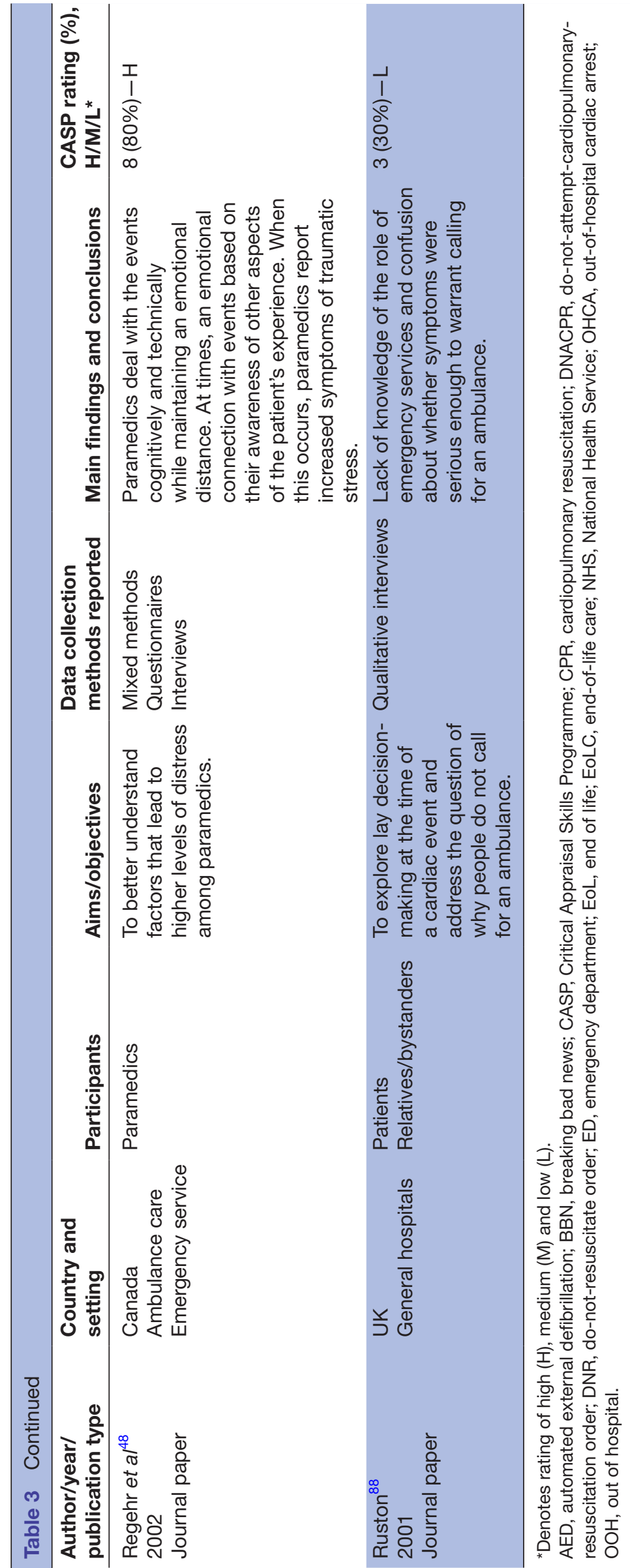


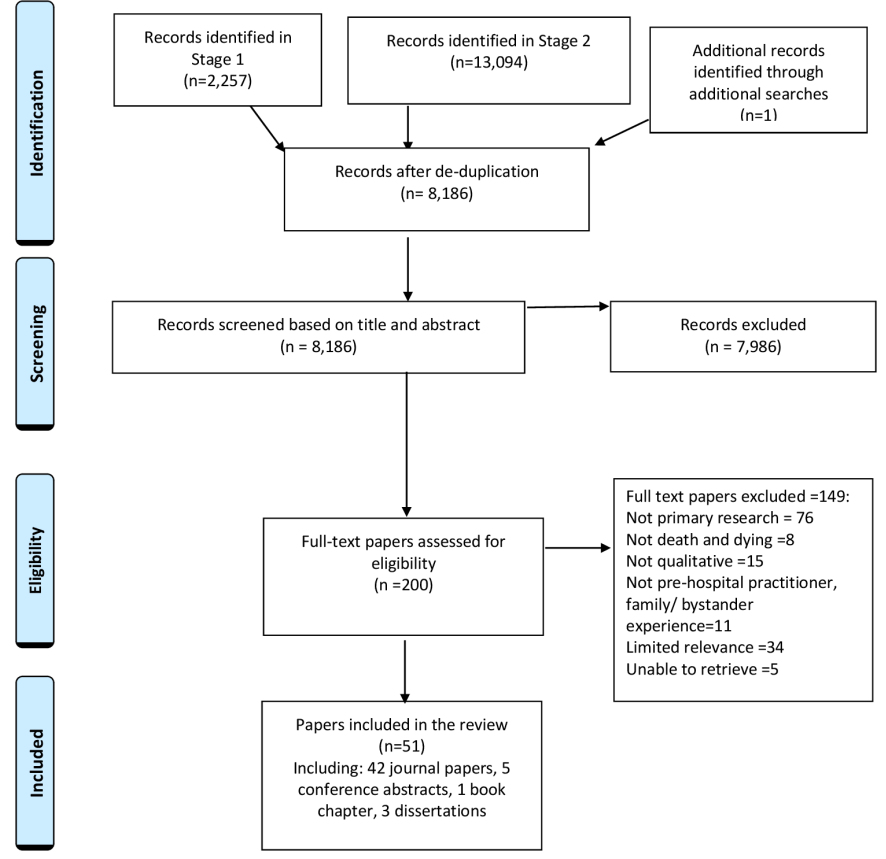

Figure 2 Preferred Reporting Items for Systematic Reviews and Meta-Analyses Extension for Scoping Reviews (PRISMA$\mathrm{ScR}$ ) flow diagram. ${ }^{35}$

Resuscitation and OHCA were also described as particularly intense and stressful experiences, characterised by intense emotions. ${ }^{55}$ 67-71 $\mathrm{PHPs}$ described complex decision-making around cardiac arrests, ${ }^{65}$ the technical abilities required alongside providing holistic care ${ }^{72}$ and difficult processes of negotiation with coworkers, other HCPs and families. There was inadequate communication around out-of-hospital DNACPR orders. ${ }^{73-75}$

\section{Managing the work of death and dying}

PHPs used a variety of strategies to manage the work of caring for patients who died or were dying, such as collecting as much on-scene information as possible before arrival, especially when attending OHCAs. ${ }^{67}$ This was important for understanding the context and dealing with emotional aspects. While on scene, coping strategies such as detachment, surface acting, ${ }^{42} 53$ humour ${ }^{42}$ and, in the case of suicides, focusing on survivors were used. Despite the psychological and physiological impact of caring for patients and relatives in prehospital contexts of death and dying PHPs also identified personal meaning, such as identifying with families because of their own experience of death and rewards from work in this environment ${ }^{53}$ including a sense of pride from a job well done. $^{76}$

\section{Perceptions on the presence of families}

The presence of family members and bystanders when attending death and dying calls provoked mixed reactions from PHPs, irrespective of context (eg, OHCA, EoLC).$^{5571}$ During OHCAs, some PHPs preferred families not to be present in the room during resuscitation and described feeling pressure from families, and expressions of disquiet related to their presence. ${ }^{69}$ Others considered that relatives could aid resuscitation by putting on hold their own feelings and emotions, thus helping PHPs focus on the condition of the patient. ${ }^{76} 77$ PHPs and families could provide mutual reassurance following unsuccessful resuscitations, that efforts were not inappropriate. ${ }^{76}$ Where there were conflicts with family members, for example, over resuscitation, ${ }^{76}$ staff managed these tensions by assigning them roles in the resuscitation efforts, such as giving them a bag of fluids to hold. ${ }^{78}$ The feeling that relatives were being useful could help prevent tensions from escalating.

\section{Training and education needs}

A lack of sufficient training around communication and relational aspects of death and dying, palliative and EoLC, $24254358-607980$ OHCA and DNACPR, 67697375 death notifications ${ }^{24}{ }^{25}$ and breaking bad news ${ }^{55} 69$ was evident in the review. PHPs identified deficits in training around DNACPR orders, ${ }^{73} 75$ dealing with suicide, ${ }^{46}{ }^{52-54}$ managing bereavement, ${ }^{71}$ communicating bad news and emotion work. ${ }^{47069}$ PHPs attending OHCAs felt training did not adequately prepare them to manage families during cardiac arrests. ${ }^{69}$ In addition to better training, papers identified a need for national-level guidance and documentation around resuscitation. ${ }^{73}$ PHPs described learning on the job through observing their colleagues, ${ }^{69}$ and wanted training and mentoring from other HCPs and peers. ${ }^{67}$

\section{Support needs}

In a work environment, characterised by intense emotional demands, PHPs reported a need for several dimensions of support not always available, including time out periods, protected time after stressful calls, and colleague, supervisor and management support. ${ }^{50}{ }^{51} \mathrm{~A}$ physical space for reflection and collective support from peers was especially important. ${ }^{50}{ }^{51}$ Support received from management and at an organisational level was described as mixed ranging from positive, empathic support and provision of time out, ${ }^{5051}$ to an absence of a climate of care $^{52}$ and lack of concern from management. ${ }^{50518182}$ Staff described the stigma surrounding expressions of stress experienced within organisations ${ }^{50} 51$ and while professional services and peer support services were available, ${ }^{52}$ uptake of these was variable, with concerns raised about being treated as an 'outcast' for accessing such services.

\section{Experiences, impact and needs of families}

Few papers focused on family and significant others' experiences, but those that did reported the lasting impact of these events. ${ }^{616870778384}$ Included papers reported on family experiences in prehospital palliative and EoLC, ${ }^{616883}$ OHCA, $^{70}{ }^{77}$ resuscitation ${ }^{76}$ and suicide. ${ }^{84}$ Witnessing a family member die or dying was reported as having a significant effect on relatives and particularly at OHCAs, families experienced a range of emotions, 
including reactions of shock, vulnerability, responsibility and hopelessness. ${ }^{70}$

\section{Experiences of behaviour and communication}

Families described witnessing PHPs exhibiting calm and control in difficult situations, and this included interactions with parents where their adult child had died. ${ }^{77} \mathrm{In}$ general, family members reported experiencing mainly positive behaviours and communication with PHPs who provided competent care ${ }^{77}$ and in cases involving suicide showed kindness, empathy and compassion. ${ }^{84}$ In cases where there was a death of adult children, families reported being treated with dignity by PHPs. ${ }^{77}$ There were some reports of relatives experiencing negative interactions with PHPs, where they demonstrated a lack of awareness of family-centred practice, ${ }^{77}$ insensitivity or little compassion in cases of suicide. ${ }^{84}$ In such instances, families felt further training was needed.

\section{Experiences, impact and needs of bystanders}

There was a paucity of evidence around experiences and perspectives of bystanders. Papers which discussed bystander experiences, described difficulties associated with cardiac events, ${ }^{85-88}$ including identifying OHCAs. ${ }^{79}$ Bystanders reported a lack of knowledge around emergency services, confusion over patient symptoms requiring ambulance response at the time of cardiac events and differing opinions on actions needed and when to call for an ambulance. ${ }^{88}$ While the literature is limited, it appeared that irrespective of whether bystanders were passers-by or present at events, they still experienced ongoing adverse reactions. These included social and psychological disturbance (eg, guilt, self-criticism) following witnessing deaths or giving cardiopulmonary resuscitation (CPR) and automated external defibrillation (AED) at cardiac events. ${ }^{85-87}$ Møller et al described this as 'the perceptual OHCA experience' whereby bystanders ruminate 'on what more could have been done' ( $p$ S22) ${ }^{86}$ Being health educated was considered to offer some mitigation against these concerns. ${ }^{85}$ In the UK, those working in public places and trained to use AEDs for OHCA also reported negative consequences including flashbacks. ${ }^{87}$ There was an identifiable need on the part of bystanders to witness visible resuscitation efforts on the part of emergency services, for feedback following sudden deaths ${ }^{86}$ and information on patient outcomes. ${ }^{85}$

\section{DISCUSSION}

We conducted a scoping review to identify and explore factors that characterise and shape PHP, family and bystander experience of death and dying in PHC and identify gaps in knowledge that warrant further research. The review identified a developing evidence base on PHPs' experiences, particularly in the UK, Europe and North America. However, there were significant shortcomings in the literature in regard to the experiences, needs and impact of death and dying for families and bystanders.

Our review confirmed existing research of the varied and complex work of PHPs ${ }^{15}$ often requiring them to respond to a range of time-critical emergencies including cardiac events, ${ }^{89}$ placing them in situations that could be difficult to manage and which presented a range of challenges and emotional demands. This was the case for PHPs with variable expertise or length of experience and often required they used a variety of coping strategies. While PHPs reported feeling confident to undertake the clinical elements of managing a patient who was dying or who died, they often felt less prepared for handling the more emotional aspects particularly when it involved communicating bad news.

This was also the case for providing palliative and EoLC, which is an increasing part of PHP's role, particularly in the UK, USA and Canada. In the UK, issues surrounding quality of access to EoLC services and the reorganisation of ambulance services to provide support to patients at the EoL may in part explain this growth in PHC EoLC provision. ${ }^{90}$ The multiple challenges that faced PHPs attending EoLC calls often meant having to use skills of crisis and conflict management and carry out the emotional support work of death and dying for which they reported minimal preparation or training. This places additional pressures on PHPs, already faced with complex decision-making and the complexities of providing care to patients nearing the EoL, and whose actions and handling of these situations influences how people die and whether their preferences are respected. Similarly, for families, given that they may not have experienced death or dying previously, how this work is managed by PHPs is likely to influence the transition to bereavement. In the UK, the key role of PHPs in the care of those at the EoL is recognised in policy, ${ }^{91}$ and guidance on delivering EoLC ${ }^{92} 93$ and breaking bad news ${ }^{94}$ has been developed and is now reflected in their training curriculum and includes preparation for the moral work they will need to engage in as a result of the emotional challenges they are likely to encounter. ${ }^{95}$ However, the experiences identified in this review suggest that challenges remain in the application of these recommendations and training in the real-world setting of PHC. Therefore, further research is needed to understand if, for example, these challenges are a result of stress resulting from the incident or coping mechanisms, rather than inadequate training.

While the review informed our understanding of PHPs who attended at the scene, we identified little qualitative evidence related to understanding the experience or impact of death and dying on call handlers. This is despite them being the first point of contact and managing situations involving death and dying as an integral part of their role. The job of a call handler is stressful and the psychological impact of dealing with emergency calls has been widely documented elsewhere ${ }^{96}{ }^{97}$ However, currently we know little about the specific impact of dealing with these 
aspects on those undertaking this role, the challenges they face, the extent to which these are related to the nature of the role itself or organisational factors, and training and support needs. Given current concerns around the mental health of emergency service workers, and that the need for an evidence base has been highlighted recently by those who support them, ${ }^{98}$ this is clearly an omission that merits further investigation.

Papers that included family members' accounts and experiences were few and tended to focus on their interactions with HCPs, including communication and behaviours during resuscitation and cardiac events, 7076 EoLC, ${ }^{616883}$ the impact of cardiac events ${ }^{70} 7788$ and occasionally experiences of suicide. ${ }^{84}$ Generally, relatives reported positive interactions with PHPs, commenting on their confidence and calmness in attending scenes involving death and dying, and while some families reported more negative encounters, it suggests there may be a disconnect between PHPs' perceptions of the care they provide and families' experience of that care. From the minority of papers identified on bystanders' experiences, there appears to be limited support available to those who have experienced stress or other symptoms from their involvement in events such as resuscitation for OHCA, or discussions about what form such support might take. Identifying and developing support mechanisms for this group will become increasingly important with the move towards encouraging bystander CPR and public access defibrillation which are key determinants in OHCA survival prior to PHP arrival. ${ }^{99}$

A paucity of evidence relating to families and bystanders' experiences and support needs is an important knowledge gap. There may be several explanations for this limited evidence base. For example, undertaking thanatological research with families and bystanders in the PHC context is likely to present both methodological and ethical challenges perceived by researchers as potential barriers to conducting research in this area. Nevertheless, as both participants in, and observers of, death and dying in the prehospital setting, applied research that addresses questions about experiences and impact and subsequently leads to the development of appropriate interventions is essential.

\section{CONCLUSION}

This review has shown there is a broad consistency regarding the experience of PHPs in relation to dealing with death and dying. It also identified current gaps in knowledge and areas where further empirical research that addresses specific research questions is needed. In particular, the limited evidence on call handlers suggests it is imperative to explore whether their experiences and needs are the same as those PHPs who attend at scene, or if there are differences between the two groups that need to be considered. There is also a need to investigate the effectiveness of current training in order to identify if gaps exist and the translation of this knowledge into practice and how this supports a rapidly evolving service. The paucity of evidence on families and bystanders presents opportunities to investigate their experiences in greater depth so that we can begin to understand their needs and how these can be addressed. Future research to address the current knowledge gaps will be important for informing future policy and practice for managing death and dying in the prehospital context.

\section{Author affiliations}

${ }^{1}$ School of Health Sciences, University of Southampton, Southampton, UK

${ }^{2}$ York Health Economics Consortium, University of York, York, UK

${ }^{3}$ University Hospital Southampton NHS Foundation Trust, Southampton, UK ${ }^{4}$ South Central Ambulance Service NHS Foundation Trust Southern Headquarters, Otterbourne, UK

${ }^{5}$ Warwick Clinical Trials Unit, Warwick Medical School, University of Warwick, Coventry, UK

${ }^{6} \mathrm{NIHR}$ Southampton Respiratory Biomedical Research Unit, University of Southampton, Southampton, UK

Contributors MM, SL and ARi designed the review. MA developed the search strategy and performed the searches. SL, ARo, MM and JT screened the titles, abstracts and full papers. SL and ARo performed data extraction. MM, SL, ARo carried out data analysis. MM, SL and ARo drafted the manuscript. MM, SL, ARi, JT, $A R o, M A, R C, H P$ and $C D$ reviewed the paper for important intellectual content. MM, $\mathrm{SL}, \mathrm{ARi}, \mathrm{JT}, \mathrm{ARO}, \mathrm{MA}, \mathrm{RC}, \mathrm{HP}$ and $\mathrm{CD}$ approved the final version of the paper.

Funding This work was supported by the National Institute for Health Research (NIHR) through the Collaboration for Leadership in Applied Health Research and Care Wessex (NIHR CLAHRC Wessex) programme.

Disclaimer The views expressed are those of the authors and not necessarily those of the NHS, the NIHR or the Department of Health and Social Care. The funders had no role in study design, data collection and analysis, decision to publish, or preparation of the manuscript.

Competing interests Alison Richardson is a National Institute for Health Research (NIHR) senior investigator. HP is in receipt of an NIHR Clinical Doctoral Fellowship.

Patient consent for publication Not required.

Provenance and peer review Not commissioned; externally peer reviewed.

Data availability statement Data sharing not applicable as no data sets generated and/or analysed for this study. No additional data are available.

Open access This is an open access article distributed in accordance with the Creative Commons Attribution 4.0 Unported (CC BY 4.0) license, which permits others to copy, redistribute, remix, transform and build upon this work for any purpose, provided the original work is properly cited, a link to the licence is given, and indication of whether changes were made. See: https://creativecommons.org/ licenses/by/4.0/.

ORCID iD

Michelle Myall http://orcid.org/0000-0001-8733-7412

\section{REFERENCES}

1 Sun JH, Shing R, Twomey M, et al. A strategy to implement and support pre-hospital emergency medical systems in developing, resource-constrained areas of South Africa. Injury 2014;45:31-8.

2 Hung KKC, Cheung CSK, Rainer TH, et al. Ems systems in China. Resuscitation 2009;80:732-5.

3 National Audit Office. NHS ambulance services: report to the Comptroller and auditor General. National Audit Office, 2017. https://www.nao.org.uk/report/nhs-ambulance-services/

4 Tippett VC, Toloo GS, Eeles D, et al. Universal access to ambulance does not increase overall demand for ambulance services in Queensland, Australia. Aust Health Rev 2013;37:121-6.

5 Troske S, Davis A. Ambulance services for Medicare beneficiaries: state differences in usage, 2012-2014. Rural and underserved health research centre publications, 2017. Available: https:// uknowledge.uky.edu/cgi/viewcontent.cgi? referer=\&httpsredir=1\& article $=1000 \&$ context=ruhrc_reports [Accessed 29 Nov 2019]. 
6 Al-Shaqsi S. Current challenges in the provision of ambulance services in New Zealand. Int J Emerg Med 2010;3:213-7.

7 Health and Social Care Information Centre. Ambulance services, England 2014-2015, 2015. Available: https://digital.nhs.uk/dataand-information/publications/statistical/ambulance-services/ ambulance-services-england-2014-15 [Accessed 29 Nov 2019].

8 Meisel ZF, Pines JM, Polsky D, et al. Variations in ambulance use in the United States: the role of health insurance. Acad Emerg Med 2011;18:1036-44

9 Andrew E, Nehme Z, Cameron P, et al. Drivers of increasing emergency ambulance demand. Prehosp Emerg Care 2020;24:385

10 Coster JE, Turner JK, Bradbury D, et al. Why do people choose emergency and urgent care services? a rapid review utilizing a systematic literature search and narrative synthesis. Acad Emerg Med 2017;24:1137-49

11 Lowthian JA, Jolley DJ, Curtis AJ, et al. The challenges of population ageing: accelerating demand for emergency ambulance services by older patients, 1995-2015. Med J Aust 2011;194:574-8.

12 Darnell G, Mason SM, Snooks H. Elderly falls: a national survey of UK ambulance services. Emerg Med J 2012;29:1009-10.

13 Zhou Y, Abel G, Warren F, et al. Do difficulties in accessing in-hours primary care predict higher use of out-of-hours GP services? Evidence from an English national patient survey. Emerg Med $J$ 2015;32:373-8.

14 Togher FJ, O'Cathain A, Phung V-H, et al. Reassurance as a key outcome valued by emergency ambulance service users: a qualitative interview study. Health Expect 2015;18:2951-61.

15 Wankhade P. Staff perceptions and changing role of pre-hospital profession in the UK ambulance services. International Journal of Emergency Services 2016;5:126-44.

16 Azeli Y, Barbería E, Jiménez-Herrera M, et al. The ReCaPTa study - a prospective out of hospital cardiac arrest registry including multiple sources of surveillance for the study of sudden cardiac death in the Mediterranean area. Scand J Trauma Resusc Emerg Med 2016;24:127.

17 Nerla R, Webb I, MacCarthy P. Out-Of-Hospital cardiac arrest: contemporary management and future perspectives. Heart 2015;101:1505-16.

18 Hawkes C, Booth S, Ji C, et al. Epidemiology and outcomes from out-of-hospital cardiac arrests in England. Resuscitation 2017;110:133-40.

19 Out of hospital cardiac arrest outcomes registry, 2016. Available: https://warwick.ac.uk/fac/sci/med/research/ctu/trials/ohcao/ publications/showcase/57904_ctu_report-final.pdf [Accessed 29 Nov 2019].

20 Hart J, Phillips P. Managing common end-of-life cancer presentations according to the evidence. Journal of Paramedic Practice 2019;11:190-6.

21 Waldrop DP, Clemency B, Lindstrom HA, et al. "We Are Strangers Walking Into Their Life-Changing Event": How Prehospital Providers Manage Emergency Calls at the End of Life. J Pain Symptom Manage 2015;50:328-34

22 Christopher S. Dealing with death and dying: a paramedic's perspective. Ambulance UK 2005;20:9-14.

23 Joint Royal Colleges Ambulance Liasion Committee and Association of Ambulance Chief Executives. JRCALC clinical Guidlelines. Bridgewater: Class Professional Publishing, 2019.

24 Douglas L, Cheskes S, Feldman M, et al. Death notification education for paramedics: past, present and future directions. Journal of Paramedic Practice 2013;5:152-9.

25 Douglas L, Cheskes S, Feldman M, et al. Paramedics' experiences with death notification: a qualitative study. Journal of Paramedic Practice 2012;4:533-9.

26 Steen E, Naess AC, Steen PA. Paramedics organizational culture and their care for relatives of cardiac arrest victims. Resuscitation 1997;34:57-63.

27 Bailey C, Murphy R, Porock D. Professional tears: developing emotional intelligence around death and dying in emergency work. $J$ Clin Nurs 2011;20:3364-72.

28 Peterson JL, Johnson MA, Halvorsen B, et al. What is it so stressful about caring for a dying patient? A qualitative study of nurses' experiences. Int J Pall Med 2013;16:181-7.

29 Ostlere L. I am a paramedic working in the coronavirus crisis - some patients have left it too late to call'. The Independent. Available: https://www.independent.co.uk/life-style/health-andfamilies/paramedic-nhs-ppe-coronavirus-covid-19-a9493456.html [Accessed 4 May 2020].

30 Townsend R, Eburn M. COVID-19 - legal and ethical implications for your practice. Australasian Journal of Paramedicine 2020;17.

31 Healthcare Resilience Task Force Behavioral Health Work Group. Managing patient and family distress associated with COVID-19 in the prehospital care setting. American College of emergency physicians, 2020. Available: https://www.acep.org/corona/covid19-field-guide/personalwell-being-and-resilience/managing-patientand-family-distress-associated-with-covid-19-in-the-prehospitalcare-setting/

32 Jameton A. Nursing practice: the ethical issues. Englewood Cliffs: Prentice Hall, 1984.

33 Campbell SM, Ulrich CM, Grady C. A Broader Understanding of Moral Distress. In: Ulrich C, Grady C, eds. Moral distress in the health professions. Springer, Cham, 2018.

34 Hobgood C, Mathew D, Woodyard DJ, et al. Death in the field: teaching paramedics to deliver effective death notifications using the educational intervention "GRIEV_ING". Prehosp Emerg Care 2013;17:501-10.

35 Tricco AC, Lillie E, Zarin W, et al. PRISMA extension for scoping reviews (PRISMA-ScR): checklist and explanation. Ann Intern Med 2018; 169:467-73

36 Pham MT, Rajić A, Greig JD, et al. A scoping review of scoping reviews: advancing the approach and enhancing the consistency. Res Synth Methods 2014;5:371-85.

37 Davis K, Drey N, Gould D. What are scoping studies? A review of the nursing literature. Int $J$ Nurs Stud 2009;46:1386-400.

38 Arksey H, O'Malley L. Scoping studies: towards a methodological framework. Int J Soc Res Methodol 2005;8:19-32.

39 Levac D, Colquhoun H, O'Brien KK. Scoping studies: advancing the methodology. Implement Sci 2010;5:69.

40 Critical Appraisal Skills Programme. CASP quality assessment Toolqualitative checklist online, 2018. Available: https://casp-uk.net/ [Accessed 6 Jan 2020].

41 Braun V, Clarke V. Using thematic analysis in psychology. Qual Res Psychol 2006;3:77-101.

42 Clompus SR, Albarran JW. Exploring the nature of resilience in paramedic practice: a psycho-social study. Int Emerg Nurs 2016;28:1-7.

43 Kirk A, Crompton PW, Knighting K, et al. Paramedics and their role in end-of-life care: perceptions and confidence. Journal of Paramedic Practice 2017;9:71-9.

44 Davey PJ, Lees AB, Godbold R. Exploring New Zealand paramedic attitudes towards advance directives: an ethical analysis. Australasian Journal of Paramedicine 2016;13.

45 Hochschild AR. The managed heart: the Commercialization of human feeling. Second ed. CA: University of California Press, 2012

46 Nilsson C, Bremer A, Blomberg K, et al. Responsibility and compassion in prehospital support to survivors of suicide victim Professionals' experiences. Int Emerg Nurs 2017;35:37-42.

47 Williams A. A study of emotion work in student paramedic practice. Nurse Educ Today 2013;33:512-7.

48 Regehr C, Goldberg G, Hughes J. Exposure to human tragedy, empathy, and trauma in ambulance paramedics. $A m ~ J$ Orthopsychiatry 2002;72:505-13.

49 Dow DM. Exploring Stress in EMS: A Challenge, Occupational Hazard, and Barrier: A Qualitative Study [PhD. Cardinal Stritch University, 2018.

50 Halpern J, Gurevich M, Schwartz B, et al. What makes an incident critical for ambulance workers? emotional outcomes and implications for intervention. Work Stress 2009;23:173-89.

51 Halpern J, Gurevich M, Schwartz B, et al. Interventions for critical incident stress in emergency medical services: a qualitative study. Stress and Health 2009;25:139-49.

52 Gallagher S, McGilloway S. Living in critical times: the impact of critical incidents on frontline ambulance personnel-a qualitative perspective. Int J Emerg Ment Health and Human Resilience 2008;9:215-24.

53 Wines M. Multifaceted traumatization: Direct and vicarious exposure of EMS personnel who responded to a suicide where loved ones of the deceased were present $[P h D$. Duquesne University, 2016.

54 Rant B, Bregar B. Understanding the attitudes of paramedics towards suicidal patients. Obzornik zdravstvene nege 2014;48:177-94.

55 Fernández-Aedo I, Pérez-Urdiales I, Unanue-Arza S, et al. A qualitative study about experiences and emotions of emergency medical technicians and out-of-hospital emergency nurses after performing cardiopulmonary resuscitation resulting in death. Enferm Intensiva 2017;28:57-63.

56 Munday D, Clerici J, Karasouli E, et al. Experiences of paramedics in managing patients with advanced chronic obstructive pulmonary disease (COPD) and advanced cancer. Palliat Med 2014;28:717-8.

57 Donnelly C, Yancey A, Johnson K, et al. Emergency medical services providers' knowledge, attitudes, and experiences responding to patients with end-of-life emergencies (S727). J Pain Symptom Manage 2015;49:421. 
58 Lord B, Récoché K, O'Connor M, et al. Paramedics' perceptions of their role in palliative care: analysis of focus group transcripts. $J$ Palliat Care 2012;28:36-40.

59 Waldrop DP, McGinley JM, Clemency B. The nexus between the documentation of end-of-life wishes and awareness of dying: a model for research, education and care. J Pain Symptom Manage 2018;55:522-9.

60 Waldrop DP, McGinley JM, Dailey MW, et al. Decision-Making in the moments before death: challenges in prehospital care. Prehosp Emerg Care 2019;23:356-63.

61 Hoare S, Kelly MP, Prothero L, et al. Ambulance staff and end-oflife hospital admissions: a qualitative interview study. Palliat Med 2018;32:1465-73.

62 Murphy-Jones G, Timmons S. Paramedics' experiences of end-oflife care decision making with regard to nursing home residents: an exploration of influential issues and factors. Emerg Med $J$ 2016;33:722-6.

63 Wilson DM, Birch S. Moving from place to place in the last year of life: a qualitative study identifying care setting transition issues and solutions in Ontario. Health Soc Care Community 2018;26:232-9.

64 Brighton LJ, Selman LE, Bristowe K, et al. Emotional labour in palliative and end-of-life care communication: a qualitative study with generalist palliative care providers. Patient Educ Couns 2019;102:494-502.

65 Robinson L, Dickinson C, Bamford C, et al. A qualitative study: professionals' experiences of advance care planning in dementia and palliative care, 'a good idea in theory but...'. Palliat Med 2013;27:401-8

66 Waldrop D, McGinley J. Emergency end of life calls in long term care: through the lens of pre-hospital providers. Gerontologist 2016;56:56

67 Anderson NE, Gott M, Slark J. Beyond prognostication: ambulance personnel's lived experiences of cardiac arrest decision-making. Emerg Med J 2018;35:208-13.

68 Ortega-Galán Ángela M, Ruiz-Fernández MD, Ortiz-Amo R, et al. Care received at the end of life in emergency services from the perspective of caregivers: a qualitative study. Enferm Clin 2019;29:10-17.

69 Mainds MD, Jones C. Breaking bad news and managing family during an out-of-hospital cardiac arrest. Journal of Paramedic Practice 2018;10:292-9.

70 Bremer A, Dahlberg K, Sandman L. Experiencing out-of-hospital cardiac arrest: significant others' lifeworld perspective. Qual Health Res 2009;19:1407-20.

71 Bremer A, Dahlberg K, Sandman L. Balancing between closeness and distance: emergency medical services personnel's experiences of caring for families at out-of-hospital cardiac arrest and sudden death. Prehosp Disaster Med 2012;27:42-52.

72 Walker WM. Emergency care staff experiences of lay presence during adult cardiopulmonary resuscitation: a phenomenological study. Emerg Med J 2014;31:453-8.

73 Moffat S, Fritz Z, Slowther A-M, et al. 'Do not attempt CPR' in the community: the experience of ambulance clinicians. Journal of Paramedic Practice 2019;11:198-204.

74 Andrus SMC. New Jersey volunteer emergency medical technicians (EMTs) out of hospital do not resuscitate orders (OOHDNRs), cardiopulmonary resuscitation (CPR), and living wills: A moral conflict [DM.H. Drew University, 2007.

75 Armitage E, Jones C. Paramedic attitudes towards DNACPR orders. Journal of Paramedic Practice 2017;9:445-52.

76 Masquelier E, Vandecasteele T, Verhaeghe S. Family presence during resuscitation: perspective of family members and emergency care providers. Resuscitation 2015:96:31.

77 Fallat ME, Barbee AP, Forest R, et al. Perceptions by families of emergency medical service interventions during imminent pediatric out-of-hospital death. Prehosp Emerg Care 2019:23:241-8

78 Muller T, van der Giessen M. "If he dies, I'll kill you". Violence, paramedics and impression management. In: Muller T, ed. Contributions from European symbolic Interactionists: conflict and cooperation. Bingley: Emerald Group Publishing Ltd, 2015: 177-93.

79 Rogers IR, Shearer FR, Rogers JR, et al. Paramedics' perceptions and educational needs with respect to palliative care. Australasian Journal of Paramedicine 2015;12:3.

80 Jensen JL, Travers AH, Marshall EG, et al. Insights into the implementation and operation of a novel paramedic long-term care program. Prehosp Emerg Care 2014;18:86-91.
81 Jonsson A, Segesten $\mathrm{K}$. The meaning of traumatic events as described by nurses in ambulance service. Accid Emerg Nurs 2003;11:141-52.

82 Jonsson A, Segesten K. Guilt, shame and need for a container: a study of post-traumatic stress among ambulance personnel. Accid Emerg Nurs 2004;12:215-23.

83 Carter AJE, Arab M, Harrison M, et al. Paramedics providing palliative care at home: a mixed-methods exploration of patient and family satisfaction and paramedic comfort and confidence. CJEM 2019;21:513-22.

84 Peters K, Cunningham C, Murphy G, et al. Helpful and unhelpful responses after suicide: experiences of bereaved family members. Int J Ment Health Nurs 2016;25:418-25.

85 Mathiesen WT, Bjørshol CA, Braut GS, et al. Reactions and coping strategies in lay rescuers who have provided CPR to out-ofhospital cardiac arrest victims: a qualitative study. BMJ Open 2016;6:e010671.

86 Møller TP, Fjordholt MC, Hansen CM, et al. Feedback to bystanders after performing CPR in out of hospital cardiac arrest (OHCA). Resuscitation 2013;84:S21-2.

87 Timmons S, Crosbie B, Harrison-Paul R. Displacement of death in public space by lay people using the automated external defibrillator. Health Place 2010;16:365-70.

88 Ruston A. Accessing emergency care at the time of a heart attack: why people do not dial 999 for an ambulance. $J R$ Soc Promot Health 2001;121:243-7.

89 Outcomes Registry Team. Out of hospital cardiac arrest outcomes (OHCAO) registry review of the first 5 years and forward strategy, 2018. Available: https://warwick.ac.uk/fac/sci/med/research/ctu/ trials/ohcao/publications/showcase/57904_ctu_report-final.pdf [Accessed 29 Nov 2019].

90 University of Sheffield Medical Research Centre. Building the evidence base in pre-hospital urgent and emergency care: a review of research evidence and priorities for future research, 2010. Available: https://assets.publishing.service.gov.uk/government/ uploads/system/uploads/attachment_data/file/216064/dh_117198. pdf [Accessed 29 Nov 2019].

91 Department of Health. End of life care strategy: promoting high quality care for adults at the end of their life. London, 2008. Available: https://assets.publishing.service.gov.uk/government/ uploads/system/uploads/attachment_data/file/136431/End_of_life_ strategy.pdf [Accessed 29 Nov 2019].

92 National End of Life Care Programme. The route to success in end of life care - achieving quality in the ambulance services, 2012. Available: https://www.england.nhs.uk/improvement-hub/ wp-content/uploads/sites/44/2017/11/End-of-Life-Care-Route-toSuccess-ambulance-services.pdf [Accessed 29 Nov 2019].

93 Public Health England. National end of life care intelligence network: ambulance data project for end of life care, London, 2015. Available: https://webarchive.nationalarchives.gov.uk/ 20190501131854/http://www.endoflifecare-intelligence.org.uk/ resources/publications/ambulance [Accessed 29 Nov 2019].

94 Dom T. Breaking bad news. clinical update. London: London Ambulance Services NHS Trust, 2011. https://www. londonambulance.nhs.uk/health-professionals/hcp-information/ documents-and-guidelines/

95 College of Paramedics. Paramedic curriculum guidance. Fifth Edition, 2019. https://www.collegeofparamedics.co.uk/publications/ professional-standards

96 Golding SE, Horsfield C, Davies A, et al. Exploring the psychological health of emergency dispatch centre operatives: a systematic review and narrative synthesis. PeerJ 2017;5:e3735.

97 Adams K, Shakespeare-Finch J, Armstrong D. An interpretative phenomenological analysis of stress and well-being in emergency medical dispatchers. Journal of Loss and Trauma 2015;20:430-48.

98 Mind Blue Light Programme. Phase three new Audience scoping: 999 call handlers final report 2016:1-33. Available: https://www. mind.org.uk/media/24690335/blue-light-programme_999-callhandler-scoping-report.pdf [Accessed 29 Nov 2019].

99 Holmberg MJ, Vognsen M, Andersen MS, et al. Bystander automated external defibrillator use and clinical outcomes after outof-hospital cardiac arrest: a systematic review and meta-analysis. Resuscitation 2017;120:77-87.

100 Hitt A, Williams J, Edwards T. Ermergency medical dispatch: do the dead take priority over the dying. Emerg.Med J 2015;32.

101 Regehr C. Public inquiries into deaths in care: effects on emergency responders. Australasian Journal of Disaster and Trauma Studies 2003;1:607-22. 